\title{
The Secreted Glycoprotein Reelin Suppresses the Proliferation and Regulates the Distribution of Oligodendrocyte Progenitor Cells in the Embryonic Neocortex
}

\author{
Himari Ogino, ${ }^{1}$ Tsuzumi Nakajima, ${ }^{1}$ Yuki Hirota, ${ }^{2}$ Kohki Toriuchi, ${ }^{3}$ Mineyoshi Aoyama, ${ }^{3}$ Kazunori Nakajima, ${ }^{2}$ \\ and ${ }^{\circledR}$ Mitsuharu Hattori ${ }^{1}$ \\ ${ }^{1}$ Department of Biomedical Science, Graduate School of Pharmaceutical Sciences, Nagoya City University, Nagoya 467-8603, Japan, ${ }^{2}$ Department of \\ Anatomy, Keio University School of Medicine, Tokyo 160-8582, Japan, and ${ }^{3}$ Department of Pathobiology, Graduate School of Pharmaceutical \\ Sciences, Nagoya City University, Nagoya 467-8603, Japan
}

Oligodendrocyte (OL) progenitor cells (OPCs) are generated, proliferate, migrate, and differentiate in the developing brain. Although the development of OPCs is prerequisite for normal brain function, the molecular mechanisms regulating their development in the neocortex are not fully understood. Several molecules regulate the tangential distribution of OPCs in the developing neocortex, but the cue molecule(s) that regulate their radial distribution remains unknown. Here, we demonstrate that the secreted glycoprotein Reelin suppresses the proliferation of OPCs and acts as a repellent for their migration in vitro. These functions rely on the binding of Reelin to its receptors and on the signal transduction involving the intracellular protein Dab1. In the late embryonic neocortex of mice with attenuated Reelin signaling [i.e., Reelin heterozygote-deficient, Dab1 heterozygote-deficient mutant, or very low-density lipoprotein receptor (VLDLR)-deficient mice], the number of OPCs increased and their distribution shifted toward the superficial layers. In contrast, the number of OPCs decreased and they tended to distribute in the deep layers in the neocortex of mice with abrogated inactivation of Reelin by proteolytic cleavage, namely a disintegrin and metalloproteinase with thrombospondin type 1 motifs 3 (ADAMTS-3)-deficient mice and cleavageresistant Reelin knock-in mice. Both male and female animals were used. These data indicate that Reelin-Dab1 signaling regulates the proliferation and radial distribution of OPCs in the late embryonic neocortex and that the regulation of Reelin function by its specific proteolysis is required for the normal development of OPCs.

Key words: Dab1; migration; neocortex; oligodendrocyte progenitor cell; Reelin

Significance Statement

Here, we report that Reelin-Dab1 signaling regulates the proliferation and radial distribution of OPCs in the late embryonic mouse neocortex. Oligodendrocyte (OL) progenitor cells (OPCs) express Reelin signaling molecules and respond to Reelin stimulation. Reelin-Dab1 signaling suppresses the proliferation of OPCs both in vitro and in vivo. Reelin repels OPCs in vitro, and the radial distribution of OPCs is altered in mice with either attenuated or augmented Reelin-Dab1 signaling. This is the first report identifying the secreted molecule that plays a role in the radial distribution of OPCs in the late embryonic neocortex. Our results also show that the regulation of Reelin function by its specific proteolysis is important for the normal development of OPCs.

Received Jan. 12, 2020; revised Aug. 21, 2020; accepted Aug. 31, 2020.

Author contributions: H.O. and M.H. designed research; H.O., T.N., Y.H., and K.T. performed research; H.O., T.N., and M.H. analyzed data; H.O., M.A., K.N., and M.H. wrote the paper.

This work was supported by JSPS Grants-in-Aid for Scientific Research 17H03895, 17K19500, and JP20H03384 (to M.H.), 16K10101 (to M.A.), 16H06482 (to K.N.), 17K07415 (to Y.H.), and 17J10967 (to H.0.); ACT-M (ACceleration Transformative research for Medical innovation) Grants 16im0210602h0001 and 17im0210602h0002 of the Japan Agency for Medical Research and Development (to M.H.); Takeda Science Foundation (K.N.); Keio Gijuku Academic Development Funds (K.N.); Keio Gijuku Fukuzawa Memorial Fund for the Advancement of Education and Research (K.N.); and Ono Medical Research Foundation (M.H.). H.O. is Research Fellow of Japan Society for the Promotion of Science (DC1).
We thank Drs. Tom Curran (Children's Research Institute at Children's Mercy Hospital, MO, USA), Junichi Takagi (Osaka University, Japan), and Katsuhiko Mikoshiba (ShanghaiTech University, China) for generously providing reagents. We greatly appreciate Prof. Masahiro Tohkin (Nagoya City University) for his professional advice on the statistical analyses. We thank Drs. Takao Kohno, Hitomi Tsuiji (Nagoya City University), Tadashi Nomura, Hitoshi Gotoh, Katsuhiko Ono (Kyoto Prefectural University of Medicine), and Rieko Muramatsu (National Center for Neurology and Psychiatry, Japan) for their insightful comments.

The authors declare no competing financial interests.

Correspondence should be addressed to Mitsuharu Hattori at mhattori@phar.nagoya-cu.ac.jp.

https://doi.org/10.1523/JNEUROSCI.0125-20.2020

Copyright $\odot 2020$ the authors 


\section{Introduction}

Oligodendrocytes (OLs) are the glial cells that form myelin sheaths and thereby facilitate the saltatory conduction of action potentials in the central nervous systems. OLs are differentiated from OL progenitor cells (OPCs), and the number, position, and timing of OPC differentiation are spatiotemporally regulated throughout life (Mayoral and Chan, 2016; Elbaz and Popko, 2019). Accordingly, abnormalities in OPC development or function are involved in the pathogenesis of many neurologic diseases (Fields, 2008; De Strooper and Karran, 2016; Birey et al., 2017; Chen et al., 2018). Thus, it is important to understand how OPC development is regulated in the central nervous system.

OPCs of the mouse neocortex arise from three different regions in the distinct developmental stages (Marshall et al., 2003; Kessaris et al., 2006; Bergles and Richardson, 2016). The first and second OPC populations arise from the medial ganglionic eminence (MGE) at around embryonic day (E) 12 and from the lateral ganglionic eminence (LGE) at around E15, respectively. While proliferating, they tangentially migrate into the neocortex. The third OPC population is derived from the $\mathrm{Emxl}^{+}$ neural progenitors in the neocortical ventricular zone (VZ) at late embryonic stages (Kessaris et al., 2006; Bergles and Richardson, 2016; Winkler et al., 2018). Although a few molecules have been suggested to regulate the tangential migration of OPCs (Choe et al., 2014; Tsai et al., 2016), there is little information on the radial migration or distribution of OPCs in the cerebral cortex.

The secreted glycoprotein Reelin is essential for the proper migration and layering of neurons (Hirota and Nakajima, 2017). Reelin is mainly secreted by Cajal-Retzius cells located in the marginal zone (MZ) of the neocortex during the embryonic stages. Reelin exerts its function by binding to its receptors, apolipoprotein $\mathrm{E}$ receptor 2 (ApoER2; also known as LRP8) and very low-density lipoprotein receptor (VLDLR; Lane-Donovan and Herz, 2017), and induces tyrosine phosphorylation of the intracellular adaptor protein Dab1, which regulates the migration and final positioning of neurons (Hirota and Nakajima, 2017; Wasser and Herz, 2017). OPCs and OLs obtained from neonatal rat brain express Reelin, Dab1, and VLDLR in vitro (Siebert and Osterhout, 2011). In the mouse spinal cord, VLDLR is expressed in OLs from postnatal day (P)0 to P15, but not in OLs of the cerebral cortex at P15 (Zhao et al., 2007). The RNA-seq database of Allen Brain Atlas (http://celltypes.brain-map.org/rnaseq/mouse/cortexand-hippocampus) indicates that VLDLR is expressed in OPCs together with platelet-derived growth factor receptor $\alpha$ (PDGF $\alpha$ ), Olig2, and Sox10. ApoER2 and VLDLR are expressed in neurons in embryonic rodent brain (Hirota and Nakajima, 2017; Wasser and Herz, 2017), but whether they are expressed in OPCs and OLs is not known. The positioning of OLs and the myelination pattern are abnormal in both Reelin-deficient $\left(\operatorname{Reln}^{-1-}\right)$ and Dab1deficient mutant (Dab1 ${ }^{\text {yotyot }}$ ) mice (Mikoshiba et al., 1985; LeVine and Torres, 1993; Tan et al., 2009). However, because the brain structures are severely disrupted in these mice, the abnormal development of OPCs could be a secondary phenomenon resulting from the abnormal structure, and the direct effect of Reelin on OPC development is yet to be explored.

Here, we investigated the role of Reelin in the development of OPCs in vitro and in vivo. We show that Reelin suppresses the proliferation of OPCs in a Dab1-dependent manner and acts as a repellant for the migration of OPCs. The strength of Reelin signaling in relation to OPC development is regulated by specific proteolysis. We propose Reelin as the first identified extracellular molecule that plays a role in radial distribution in the late embryonic neocortex.

\section{Materials and Methods}

Antibodies and vectors

The following antibodies were purchased: mouse anti-Reelin G10 [MAB5364, RRID:AB_2179313, 1:1000 for Western blotting (WB)], mouse anti-phosphotyrosine 4G10 (05-321, RRID:AB 309678, 1:1000 for WB), and rabbit anti-Olig2 [AB9610, RRID: AB_570666, 1:500 for immunocytochemistry (ICC) and immunohistochemistry (IHC)] from Merck Millipore; anti- $\beta$-actin (AC15, A1978, RRID:AB_476692, 1:10,000 for WB) from SigmaAldrich; goat anti-Reelin (AF3820, RRID: AB_2253745, 1:1000 for IHC), goat anti-PDGFR $\alpha$ (AF1062, RRID:AB_2236897, 1:500 for IHC), and goat VLDLR (AF2258, RRID:AB_2288612, 1:500 for IHC) from R\&D Systems; rat anti-Dab1 (D355-3 and D354-3, 1:1000 for WB) from MBL; rabbit anti-Ki67 (ab15580, RRID:AB_ $443209,1: 800$ for IHC), rat anti-BrdU (ab6326, RRID:AB_305426, 1:500 for ICC) from Abcam. The rabbit anti-Dab1 antibody was prepared and affinity purified as previously described (Uchida et al., 2009; 1:1000 for WB). Alexa Fluor 488-conjugated or Alexa Fluor 594-conjugated secondary antibodies (1:400 for ICC and IHC) were purchased from Thermo Fisher Scientific. The Reelin cDNA (D'Arcangelo et al., 1997) was kindly provided by Tom Curran. The expression vector for $\mathrm{KA}_{2}$-Reelin (Yasui et al., 2007) was kindly provided by Junichi Takagi.

\section{Animals}

All experimental protocols were approved by the Animal Care and Use Committees of Nagoya City University and Keio University, and performed according to the guidelines of the National Institutes of Health of Japan. The animals were housed under a 12/12 h light/dark cycle with lights on between 6 A.M. and 6 P.M. with standard diets and water ad libitum. Timed mating was performed as follows. We started mating in the evening (typically 9 P.M.) and separated the mice next morning (typically 9 A.M.). The embryos were considered to be E0.5 on the day of the separation. The interval between the mating was at least $5 \mathrm{~d}$. Both male and female animals were used. The sex of the embryonic and neonatal animal subject was unknown to researchers. Slc:ICR mice, C57BL/6N mice, and Wistar ST rats were obtained from Japan SLC. The heterozygote reeler mouse $\left(\operatorname{Reln}^{+/-}, \mathrm{B} 6 \mathrm{C} 3 \mathrm{Fe}-\mathrm{a} / \mathrm{a}-\mathrm{rl}\right)$ was purchased from The Jackson Laboratory. The heterozygote yotari $\left(D a b 1^{+/ y o t}\right)$ mouse, in which the Dab1 gene is interrupted with a long interspersed nuclear element fragment and thus no functional Dab1 protein is produced (Sheldon et al., 1997; Yoneshima et al., 1997; Kojima et al., 2000), was kindly provided by Katsuhiko Mikoshiba. The heterozygote VLDLR-deficient $\left(\mathrm{Vldlr}^{+-}\right)$ mouse was kindly provided by Dr. Michael S. Brown and Dr. Joseph L. Goldstein (RRID: IMSR_JAX:002529, Frykman et al., 1995). They were back-crossed with Slc:ICR mice. Knockout-First heterozygous mice of a disintegrin and metalloproteinase with thrombospondin type 1 motifs 3 (ADAMTS-3; Adamts $^{+/-}$, Project ID CSD50174: Adamts $3^{\text {tmla(KOMP)Wtsi }}$; information is available at https://www.komp.org/geneinfo.php?geneid= 18334) were obtained from the Knockout Mouse Project Repository/ Welcome Trust Sanger Institute (Skarnes et al., 2011; Bradley et al., 2012). Cleavage-resistant Reelin knock-in (Reln $\left.{ }^{P A-D V / P A-D V}\right)$ mice were generated as previously described (Okugawa et al., 2020). The Adamts $3^{+/-}$and $\operatorname{Reln}^{P A-D V /+}$ mice were back-crossed with C57BL/6N mice.

\section{Genotyping}

Genomic DNA preparation was performed as previously described (Ogino et al., 2017). Genotyping for the Reln (Koie et al., 2014), Vldlr (Frykman et al., 1995; Hirota and Nakajima, 2020), Adamts3 (Ogino et al., 2017), and $\operatorname{Reln}^{P A-D V}$ (Okugawa et al., 2020) mice were performed as previously described. Dab1 $1^{\text {yot }}$ mice were genotyped by PCR (32 cycles at $94^{\circ} \mathrm{C}$ for $15 \mathrm{~s}, 64^{\circ} \mathrm{C}$ for $20 \mathrm{~s}$, and $72^{\circ} \mathrm{C}$ for $45 \mathrm{~s}$ ) using the following primers: for the wild-type (WT) allele, dab1-570 (GCCCTTCAGC ATCACCATGC T) and dab1-737 (AAAGAGATCT CTCAAGTCCA GG); for the mutant allele, dab1-570 and yot-1 (CAGTGAGTAC 
Table 1. Primer sequences used for $q R T-P C R$

\begin{tabular}{|c|c|c|c|}
\hline \multirow{3}{*}{$\begin{array}{l}\text { Gene symbol } \\
\beta \text {-Actin }\end{array}$} & \multicolumn{2}{|c|}{ Primer sequence $\left(5^{\prime} \rightarrow 3^{\prime}\right)$} & \multirow{3}{*}{$\begin{array}{l}\text { Amplification size (bp) } \\
150\end{array}$} \\
\hline & Forward & ATGGATGACGATATCGCTGC & \\
\hline & Reverse & СTTCTGACCCATACCCACCA & \\
\hline \multirow[t]{2}{*}{ Cdk2 } & Forward & CCTGCACCAGGACCTCAAGAA & 120 \\
\hline & Reverse & CGGTGAGAATGGCAGAATGCTA & \\
\hline \multirow[t]{2}{*}{ c-myc } & Forward & TCGGCTCCCCTGAAAAGAGC & 197 \\
\hline & Reverse & TCGCTCTGCTGTTGCTGGTG & \\
\hline \multirow[t]{2}{*}{ CNP } & Forward & ATTTTGGCAAGAGACCTCCA & 149 \\
\hline & Reverse & AAAGAGGGCAGAGATGGACA & \\
\hline \multirow[t]{2}{*}{ Id2 } & Forward & CGCTGACCACCCTGAACAC & 75 \\
\hline & Reverse & TCGACATAAGCTCAGAAGGGAAT & \\
\hline \multirow[t]{2}{*}{ Id4 } & Forward & CGGCGCCGTGAACAA & 139 \\
\hline & Reverse & TGGTGGCTTTTTTCTCTTAATTTCTG & \\
\hline \multirow[t]{2}{*}{ MBP } & Forward & CAAGGACTCACACACAAGAA & 65 \\
\hline & Reverse & CTTGGGTCCTCTGCGACTTC & \\
\hline \multirow[t]{2}{*}{ NG2 } & Forward & TCCTGGAGAGAGGTGGAAGA & 104 \\
\hline & Reverse & CGATCCATCTCTGAGGCATT & \\
\hline \multirow[t]{2}{*}{ Olig2 } & Forward & GCCCAGAGCCAGGTTCTCTT & 67 \\
\hline & Reverse & TTTTTCAACCTTCCGAATGTGA & \\
\hline \multirow[t]{2}{*}{ p15 } & Forward & CAGGTCATGATGATGGGCAG & 138 \\
\hline & Reverse & CATTAGCGTGTCCAGGAAGC & \\
\hline \multirow[t]{2}{*}{ p21 } & Forward & AGACACGAAACAGGCTCAGG & 87 \\
\hline & Reverse & TCGTCAACACCCTGTCTTGT & \\
\hline \multirow[t]{2}{*}{ p27 } & Forward & GTGGACCAAATGCCTGACTC & 116 \\
\hline & Reverse & CTGTTGGCCCTTTTGTTTTG & \\
\hline \multirow[t]{2}{*}{ PDGFRa } & Forward & GCCACGAAAGAGGTCAAGGA & 73 \\
\hline & Reverse & GCCTGATCTGGACGAAGCC & \\
\hline \multirow[t]{2}{*}{ Sox5 } & Forward & GGAGGAGCTGATCAAGAACG & 83 \\
\hline & Reverse & CCAGGAGCTTGTCTTTCCAG & \\
\hline \multirow[t]{2}{*}{ Sox6 } & Forward & TGTCAACCTGCCAAACAAGA & 104 \\
\hline & Reverse & ACAGGGCAGGAGAGTTGAGA & \\
\hline \multirow[t]{2}{*}{ Sox8 } & Forward & AAGAGAGAAGGGGCTTCAGG & 114 \\
\hline & Reverse & TGTATCCTGGAGCATCCACA & \\
\hline \multirow[t]{2}{*}{ Sox9 } & Forward & СCTGGTTTCGTTCTCTGTTTTCC & 77 \\
\hline & Reverse & TCAGTTGCCCGCTCCAAA & \\
\hline \multirow[t]{2}{*}{ Sox10 } & Forward & CCGCACCTCCACAATGCT & 75 \\
\hline & Reverse & GCGCTTGTCACTCTCGTTCA & \\
\hline \multirow[t]{2}{*}{ TrkB } & Forward & GGCCGTGAAGACGCTGAA & 62 \\
\hline & Reverse & CGGCTTCGCGATGAAAGT & \\
\hline \multirow[t]{2}{*}{ TrkC } & Forward & TGCCTGATGTGGACTGGATA & 120 \\
\hline & Reverse & TGTCTTCGCTCGTCACATTC & \\
\hline
\end{tabular}

ATATTGTGTG AGTTCC). The sizes of the PCR products were $787 \mathrm{bp}$ (WT allele) and 598 bp (mutant allele), respectively.

\section{OPC culture}

OPC culture was performed essentially as described (Arai and Lo, 2009). Briefly, the neocortex from P2 to P3 Wistar/ST rats or P2 to $\mathrm{P} 4$ mice was dissected and digested with papain (Worthington, LS003124) at $37^{\circ} \mathrm{C}$ for $10-20 \mathrm{~min}$. Dissociated brain cells were resuspended in DMEM (Wako, 044-29765) supplemented with 10\% FBS (Nichirei Biosciences, 175012) and $50 \mu \mathrm{g} / \mathrm{ml}$ penicillin $/ 50$ units $/ \mathrm{ml}$ streptomycin (Nacalai Tesque, 09367-34) and were plated in $75-\mathrm{cm}^{2}$ flasks (Corning, 3275). They were then cultured for 9-12 d. When the mixed glial cells reached confluency, the flasks were shaken for $30 \mathrm{~min}$ on an orbital shaker $(100 \mathrm{rpm})$ at $37^{\circ} \mathrm{C}$ to remove microglia. After new medium was added, the flasks were shaken overnight at $37^{\circ} \mathrm{C}$. The medium was plated on uncoated culture dishes for $1 \mathrm{~h}$ at $37^{\circ} \mathrm{C}$ to eliminate astrocytes and microglia. The nonadherent cells were collected and resuspended in Neurobasal Medium (Thermo Fisher Scientific, 21103-049) supplemented with 2\% B27 (Thermo Fisher Scientific, 17503-044), 50 units/ml penicillin/streptomycin, 1\% GlutaMAX (Thermo Fisher Scientific, 35050-061), $10 \mathrm{ng} / \mu \mathrm{l}$ PDGF (Funakoshi, AF-100-13A), and $10 \mathrm{ng} / \mu \mathrm{l}$ fibroblast growth factor 2 (FGF2; Funakoshi, 100-18B). The cells were and plated on the poly-L-lysine (PLL)-coated coverslips or wells. For siRNA transfection, OPCs were seeded at $4.0 \times 10^{3} \mathrm{cells} / \mathrm{cm}^{2}$ onto the PLL-
Table 2. Changes in the mRNA expression in Reelin-treated OPCs

\begin{tabular}{llllll}
\hline Target & Fold change & $N$ & SEM & $p$ value & $q$ value \\
\hline Id2 & 0.853 & 5 & 0.0436 & 0.0280 & 0.392 \\
TrkC & 0.873 & 5 & 0.0392 & 0.0317 & 0.2219 \\
TrkB & 0.928 & 5 & 0.0398 & 0.1447 & 0.67526667 \\
PDGFR $\alpha$ & 0.923 & 5 & 0.0428 & 0.1464 & 0.5124 \\
p15 & 0.787 & 5 & 0.1299 & 0.1764 & 0.49392 \\
Cdk2 & 0.947 & 3 & 0.0306 & 0.2254 & 0.52593333 \\
p27 & 1.020 & 3 & 0.0141 & 0.2918 & 0.5836 \\
Sox6 & 0.981 & 3 & 0.0203 & 0.4481 & 0.784175 \\
Sox5 & 0.953 & 5 & 0.0720 & 0.5495 & 0.7693 \\
p21 & 0.983 & 3 & 0.0268 & 0.5907 & 0.68915 \\
Id4 & 0.965 & 5 & 0.1212 & 0.7871 & 0.7871 \\
Sox8 & 1.014 & 3 & 0.0779 & 0.8739 & 0.7646625 \\
Sox9 & 1.009 & 3 & 0.0590 & 0.8928 & 0.73524706 \\
c-myc & 0.999 & 3 & 0.0209 & 0.9662 & 0.71193684 \\
CNP & 1.035 & 3 & 0.0409 & 0.4823 & \\
Olig2 & 1.016 & 3 & 0.0244 & 0.5793 & \\
MBP & 0.958 & 5 & 0.1070 & 0.7147 & \\
Sox10 & 1.019 & 3 & 0.0774 & 0.8290 & \\
NG2 & 1.006 & 3 & 0.0517 & 0.9182 & \\
\hline
\end{tabular}

Rat OPCs were treated with or without Reelin for $24 \mathrm{~h}$. Total RNA was then extracted and the levels of genes reported to regulate the proliferation and/or differentiation of OPCs (above doublet) and the marker genes of $\mathrm{OL}$ lineage (below doublet) were examined by qRT-PCR. The data were analyzed using a one-sample $t$ test, and FDR-adjusted $q$ values are shown.

coated coverslips. Transfection was performed on the next day of seeding.

For immunoprecipitation, OPCs were seeded at $2.7 \times 10^{5}$ cells $/ \mathrm{cm}^{2}$ onto the PLL-coated wells and were incubated with control or Reelin for 20 min on day 2 or day 3 when the OPCs were almost confluent. For a proliferation assay, OPCs were seeded at $1.5 \times 10^{3}$ cells $/ \mathrm{cm}^{2}$ onto the PLL-coated coverslips. OPCs were treated with control or Reelin-containing medium on day 2 for $24 \mathrm{~h}$, and $10 \mu \mathrm{M} \mathrm{BrdU}$ was added in the last $5 \mathrm{~h}$. For quantitative RT-PCR (qRT-PCR), OPCs were seeded at $2.7 \times 10^{5}$ cells $/ \mathrm{cm}^{2}$ onto the PLL-coated wells and were incubated with control or Reelin containing medium for $24 \mathrm{~h}$ on day 2 or day 3 when OPCs reached $80-90 \%$ confluence.

A Boyden chamber assay was performed using polyethylene terephthalate filters $(8-\mu \mathrm{m}$ pore) coated with PLL in 24-well translucent cell culture inserts (Falcon, 353097) essentially as described previously (Miyamoto et al., 2008). Briefly, OPCs $\left(1 \times 10^{5}\right.$ cells for rat OPCs, $2 \times 10^{4}$ cells for mouse OPCs) in $300 \mu$ of the medium per inserts were loaded into the upper wells, while the lower wells contained $750 \mu \mathrm{l}$ of control or Reelin-containing medium with $10 \mu \mathrm{M}$ AraC. The inhibitory effect of $\mathrm{AraC}$ on the OPC proliferation was confirmed in a separate experiment (data not shown). After a 10 -min incubation at $37^{\circ} \mathrm{C}$, half of the culture medium in the inserts were changed to control or Reelin containing medium and incubated for $24 \mathrm{~h}$ at $37^{\circ} \mathrm{C}$.

For transfection of siRNA into OPCs, OPCs were transfected with 10 nM each siRNA concentration using Lipofectamine RNAiMAX Transfection Reagent (Thermo Fisher Scientific, 13778150) according to the manufacturer's protocols and incubated for $24 \mathrm{~h}$ at $37^{\circ} \mathrm{C}, 5 \% \mathrm{CO}_{2}$. siRNAs were ordered and purchased from Nippon Gene. The sequences of each siRNAs used were as follows: siVLDLR-1, sense, 5'-CAUGCCGCAUAAAUG AAAU-3'; siVLDLR-2, sense, 5'-CGCAGACUGUUCCGACCAA- $3^{\prime}$. Universal negative control siRNA (Nippon Gene) was used as a negative control.

Immunoprecipitation from OPC culture extract

OPCs were washed with PBS and solubilized in lysis buffer (20 mM Tris$\mathrm{HCl}, \mathrm{pH} 7.5,150$ mм NaCl, 5 mм EDTA, 1\% Triton X-100, 0.1\% $\mathrm{H}_{2} \mathrm{O}_{2}$, $0.05 \% \mathrm{SDS}$, and $5 \mathrm{~mm} \mathrm{Na}_{3} \mathrm{VO}_{4}$ ) with pipetting on ice. The lysates were centrifuged at $15,300 \times \mathrm{g}$ for $10 \mathrm{~min}$ at $4^{\circ} \mathrm{C}$. The supernatant was collected, mixed with anti-Dab1 antibodies (D355-3 and D354-3, $2 \mu \mathrm{g} / \mathrm{ml}$ each) and Protein G Sepharose (GE Healthcare, 17-0618-01), and rotated for $3 \mathrm{~h}$ at $4^{\circ} \mathrm{C}$. The immunoprecipitate was washed three times with lysis buffer and dissolved in SDS sampling buffer [final: $62.5 \mathrm{~mm}$ Tris- $\mathrm{HCl}$, 
$\mathrm{pH} 6.8,10 \%(\mathrm{w} / \mathrm{v})$ glycerol, $0.05 \%$ bromophenol blue, $2 \%(\mathrm{w} / \mathrm{v})$ SDS, and $5 \%(\mathrm{v} / \mathrm{v}) \quad 2$ mercaptoethanol].

ICC

OPCs were washed with ice-cold PBS and then fixed in $4 \%$ formaldehyde for $10 \mathrm{~min}$. After three washes with PBS containing 0.05\% Tween 20 (PBS-T), the OPCs were incubated with $2 \%$ bovine serum albumin in PBS for $30 \mathrm{~min}$. The cells were then incubated with primary antibodies at $4^{\circ} \mathrm{C}$, overnight. After five washes with PBS-T, they were incubated with Alexa Fluor 488-conjugated and Alexa Fluor 594-conjugated secondary antibodies for $1 \mathrm{~h}$ at room temperature in the dark. For nuclear staining, Hoechst 33342 (Invitrogen, H1399) was used. For the Boyden chamber assay, the non-migrating cells were removed by cotton-wool swabs. Migrated cells at the bottom of the filters were immunostained as described above and according to the manufacturer's instructions.

IHC

Embryonic brains were immediately immersed in $4 \%$ paraformaldehyde in PBS for $4 \mathrm{~h}$ at $4^{\circ}$ C. Fixed brains were cryoprotected by sequential immersion in $20 \%$ and $30 \%$ sucrose in PBS, embedded in OCT compound (Sakura Finetek), and quickly frozen on dry ice. The frozen brains were coronally sectioned at a thickness of $14 \mu \mathrm{m}$ using a cryostat (CM 1850; Leica Microsystems). IHC was performed as previously described (Ogino et al., 2017). Confocal images were obtained using FV1000 (Olympus) microscopes. For quantifications, we immunostained several sections from each individual mouse, observed them under the microscope, and defined the region of interest by carefully checking the shape and size of the lateral ventricle and the hippocampus and the thickness of the cortical wall. We then counted one section from the primary somatosensory cortex per mouse. The numbers of analyzed mice are given in the figure legends. In addition, in our pilot experiment, we counted several different regions along the anteroposterior axis of the primary somatosensory cortex and found that the magnitude of the difference was almost the same.

Transfection to human embryonic kidney (HEK)293T cells

HEK293T cells were cultured and transfected with plasmid DNA as described previously (Kohno et al., 2020). The culture medium was replaced with Neurobasal Medium supplemented with 2\% B27, 50 units/ $\mathrm{ml}$ penicillin/streptomycin, and 1\% GlutaMAX.

$W B$

WB was performed as previously described (Ogino et al., 2017). Dissected neocortices were homogenized in lysis buffer. Images were analyzed with ImageJ and quantified as described previously (Nakano et al., 2007).

$q R T-P C R$

Total RNA was extracted with TRIzol (Thermo Fisher Scientific, 15596026) according to the manufacturer's instructions. The quality of the extracted RNA was checked by agarose gel electrophoresis. Total RNA (400 ng) was used to synthesize cDNA using random hexamer
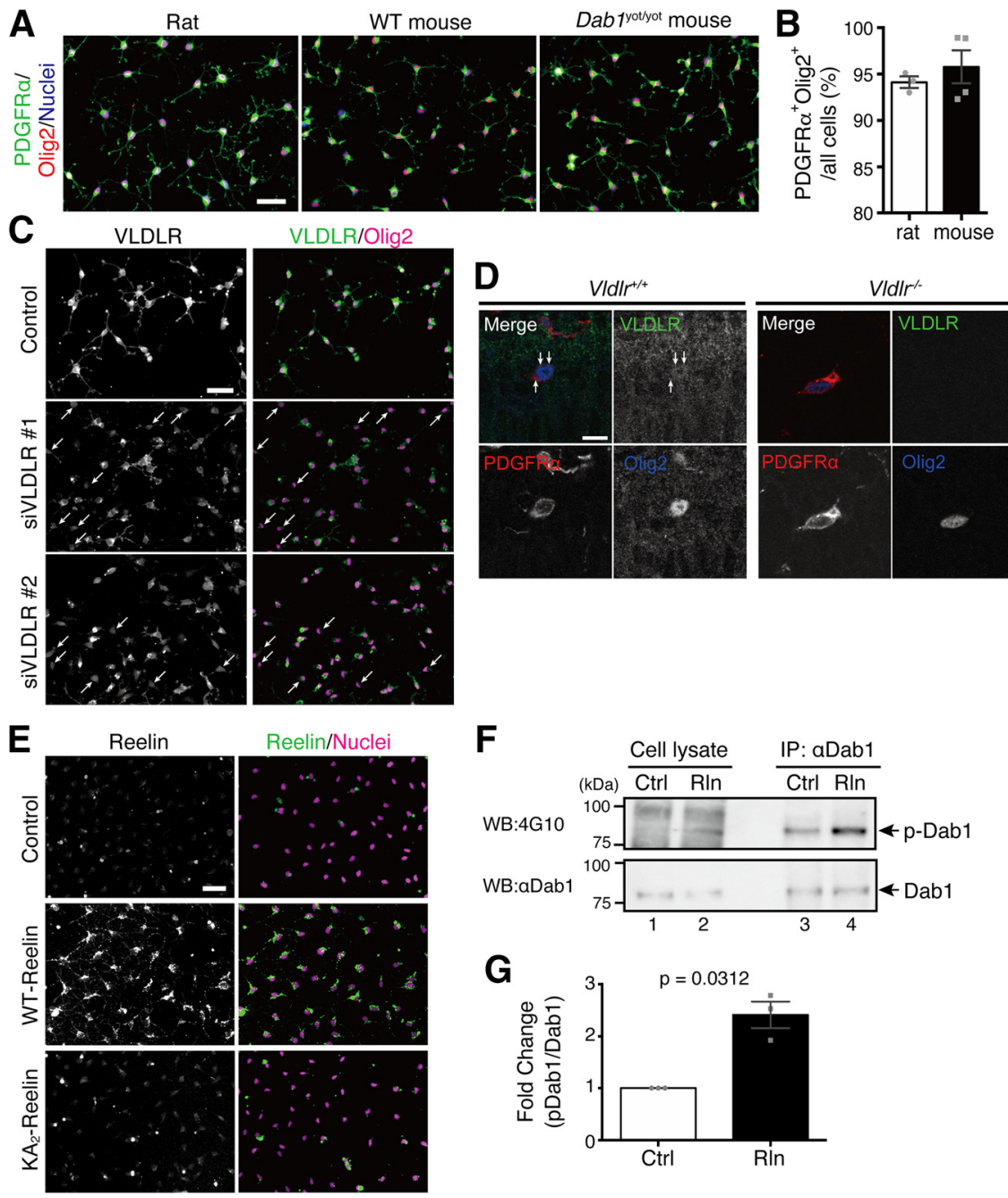

Figure 1. OPCs express canonical Reelin signaling components and respond to Reelin stimulation. A, OPCs from the animals indicated above were cultured and immunostained for PDGFR $\alpha$ (green) and Olig2 (red). Nuclei were stained with Hoechst 33342 (blue). Scale bar: $50 \mu \mathrm{m}$. B, Quantification of the percentage of PDGFR $\alpha^{+}$Olig2 ${ }^{+}$cells in OPC cultures from rat (white bar) or mouse (black bar). $N=3$ (rat), 4 (mouse). C, Rat OPCs were transfected with control (top panels) or two different kinds of siRNA for VLDLR (middle and bottom panels). OPCs were then immunostained for VLDLR (left) and Olig2. The merged images are shown on the right. Arrows indicate cells in which VLDLR signals are low. Scale bar: $50 \mu \mathrm{m}$. D, Sections of the neocortex from $\mathrm{VIdlr}^{+/+}$or $\mathrm{VIdlr}^{-1-}$ mice at E18.5 were immunostained with antibodies against VLDLR (green), PDGFR $\alpha$ (red), and Olig2 (blue). Arrows indicate VLDLR expression in PDGFR $\alpha^{+}$0lig2 $2^{+}$OPCs. Scale bar: $10 \mu \mathrm{m} . \boldsymbol{E}$, Rat OPCs were incubated for $6 \mathrm{~h}$ with vehicle only (control, top panels), WT-Reelin (middle panels), or mutant-Reelin $\left(\mathrm{KA}_{2^{-}}\right.$ Reelin, bottom panels) that cannot bind to Reelin receptors. (ells were immunostained for Reelin (left panels). Merged images with nuclei (stained with Hoechst 33342, magenta) are shown on the right. Scale bar: $50 \mu \mathrm{m}$. F, OPCs from Reln ${ }^{-1}$ mice were incubated with vehicle only (Ctrl) or WT-Reelin (RIn) for $20 \mathrm{~min}$. Dab1 was immunoprecipitated from the lysates. The samples were separated by SDS-PAGE and analyzed by WB with anti-phosphotyrosine antibody (upper panel) or antiDab1 antibody (lower panel). The positions of the molecular mass markers (kDa) are shown on the left of the panel. $\mathbf{G}$, Quantification of Dab1 phosphorylation. The data were analyzed using a one-sample $t$ test. $N=3$.

(Promega, C118A) and SuperScript III (Invitrogen, 56575) according to the manufacturer's instructions in a $20-\mu \mathrm{l}$ reaction. PCR was performed using KAPA SYBR Fast qPCR kit (Kapa Biosystems, KK4605) on a StepOnePlus (Thermo Fisher Scientific). The cycling conditions were as follows: $95^{\circ} \mathrm{C}$ for $3 \mathrm{~min}$ (one cycle), $95^{\circ} \mathrm{C}$ for $10 \mathrm{~s}$, and $60^{\circ} \mathrm{C}$ for $30 \mathrm{~s}(40$ cycles). The expression levels of all genes were normalized to the expression of $\beta$-actin and analyzed using the relative standard curve method. The sequences of primers used are described in Table 1 .

Statistical analyses

Statistical data are shown as the mean \pm SEM and individual data points are plotted. After determining whether the data follow normal distribution with a Shapiro-Wilk normality test, for normally distributed data, we performed ordinary one-way ANOVA followed by Tukey-Kramer 
A

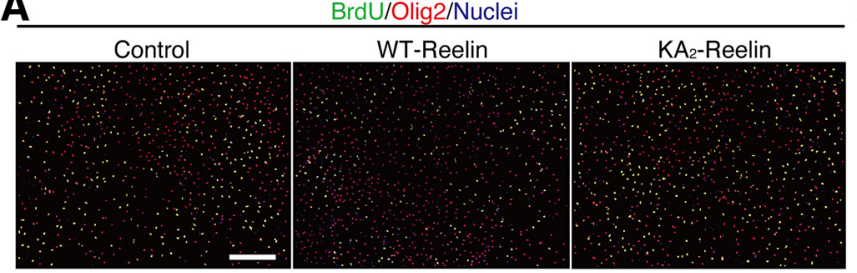

B Brdu+Olig2+cells /Olig2 ${ }^{+}$cells (\%)

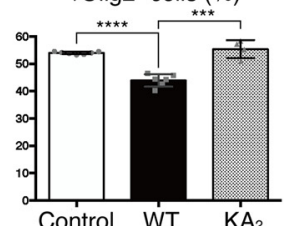

C
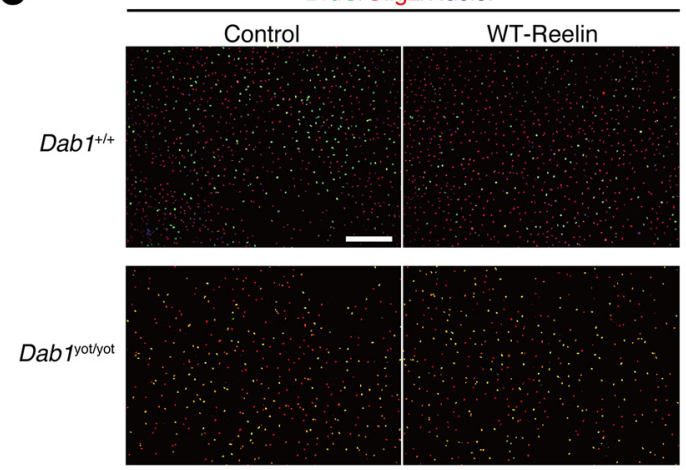

D

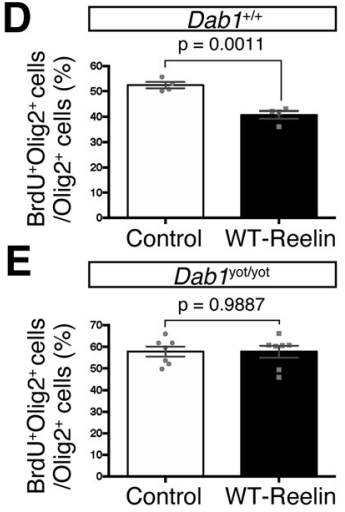

Figure 2. Reelin affects the proliferation of OPCS in a Dab1-dependent manner. $\boldsymbol{A}$, Rat OPCs were incubated with vehicle only (control, left), WT-Reelin (middle), or KA $\mathrm{K}_{2}$-Reelin (right) for $19 \mathrm{~h}$ and a further $5 \mathrm{~h}$ in the presence of BrdU. OPCs were immunostained for BrdU (green) and Olig2 (red). Nuclei were stained using Hoechst 33342 (blue). Scale bar: $300 \mu \mathrm{m}$. $\boldsymbol{B}$, Quantification of the percentage of $\mathrm{BrdU}^{+}$Olig2 ${ }^{+}$cells in rat 0 lig2 ${ }^{+} \mathrm{OPCs}$. The data were analyzed using one-way ANOVA $\left(F_{(2,15)}=19.68, p<0.0001\right)$ followed by Tukey-Kramer post hoc test; ${ }^{* * *} p<0.001$ and ${ }^{* * *} p<0.0001$. Control, $N=7$; WT-Reelin, $N=6$; KA 2 -Reelin, $N=4$. C, OPCs from Dab1 ${ }^{+/+}$(upper panels) or Dab $7^{\text {yotyot }}$ (lower panels) mice were incubated with vehicle only (control, left) or WT-Reelin (middle) for $19 \mathrm{~h}$ and a further $5 \mathrm{~h}$ in the presence of BrdU. OPCs were immunostained for BrdU (green) and Olig2 (red). Nuclei were stained using Hoechst 33342 (blue). Scale bar: $300 \mu \mathrm{m}$. D, Quantification of the percentage of $\mathrm{BrdU}^{+}$Olig2 ${ }^{+}$cells in $\mathrm{Dab}^{1^{+/}}$Olig2 ${ }^{+} \mathrm{OPCS}$. The data were analyzed using a two-tailed Student's $t$ test. $N=4$. $E$, Quantification of the percentage of BrdU $^{+} 0$ lig2 ${ }^{+}$cells in Dab1 ${ }^{\text {yot } y o t}$ Olig2 ${ }^{+} O P C$. The data were analyzed using a two-tailed Student's $t$ test. $N=7$.

post hoc test. For datasets with small sample size, which thus is not subject to Shapiro-Wilk normality test, we assume that it might show normality because the experimental datasets from the same kind of experiments showed normality, and we planned the experiments on this assumption. To compare two different groups, the one-sample $t$ test was used to compare the mean with the control value, and the two-tailed Student's test was used to compare the means of two groups. Statistical analysis details for individual experiment are described in figure legends, including the number of animals $(n)$ or of independent experiments $(N)$. For the multiple testing correction (Figs. $4 D, I, 5 C, 6 C, H, 7 C, F$; Table 2), the $p$ values were adjusted by the method described previously (Benjamini and Hochberg, 1995) to obtain false discovery rate (FDR)adjusted values ( $q$ values); $p$ or $q$ values $<0.05$ or 0.1 , respectively, were considered significant. Statistical analyses were performed with Microsoft Excel and Prism 7 (GraphPad Software).

\section{Results}

\section{Reelin suppresses OPC proliferation depending on binding} to its receptors and Dab1

To determine whether Reelin affects the development of OPCs, we obtained primary OPCs from the neonatal neocortex of rats and mice. $\sim 95 \%$ of the cells from rats (Fig. $1 A$, left panel, $B$ ) and WT mice (Fig. 1A, middle panel, $B$ ) expressed both PDGFR $\alpha$ and Olig2, an OPC marker and an OL lineage marker, respectively (Fig. 1A). These results indicated that our OPC cultures were largely homogenous. We also prepared primary OPCs from the Dab1 deficient-mutant (Dab1 $\left.{ }^{\text {yot/yot }}\right)$ mice. Again, almost all of the cells were PDGFR $\alpha^{+}$Olig2 ${ }^{+}$(Fig. $1 A$, right panel).

A previous report indicated that cultured rat OPCs express VLDLR (Siebert and Osterhout, 2011). We checked whether mouse OPCs express Reelin receptors. When the OPCs transfected with control siRNA were stained with anti-VLDLR antibody, virtually all of them gave strong signal (Fig. $1 C$, top panels). On the other hand, when the siRNA for VLDLR were transfected to the OPCs, the number of OPCs with clear VLDLR signal was greatly reduced (Fig. $1 C$, middle and bottom panels, indicated by arrows). We also found that VLDLR was also expressed by OPCs in the WT mouse neocortex but not by those of VLDLR KO mice (Fig. 1D). These results suggest that OPCs express VLDLR both in vitro and in vivo.

When the OPCs were incubated with recombinant WT-Reelin, it bound to them and appeared to be internalized (Fig. $1 E$, middle row). A Reelin mutant $\left(\mathrm{KA}_{2}{ }^{-}\right.$ Reelin) that does not bind to ApoER2 or VLDLR (Yasui et al., 2007) did not bind to the OPCs (Fig. 1E, bottom row). These results suggested that Reelin binds to canonical Reelin receptors and is endocytosed by OPCs, as reported in neurons (D’Arcangelo et al., 1999; Jossin et al., 2007; Koie et al., 2014).

To examine whether Reelin induces the tyrosine phosphorylation of Dab1 in OPCs, we cultured OPCs from Reelin-deficient $\left(\right.$ Reln $\left.^{-1-}\right)$ mice so that we could exclude the effect of endogenous Reelin. The OPCs were incubated with WT-Reelin or control medium for $20 \mathrm{~min}$, and the whole-cell lysates were prepared. Dab1 protein was immunoprecipitated from the lysate, the precipitated proteins were separated by SDS-PAGE and analyzed by WB with anti-phosphotyrosine antibody (Fig. $1 F$ ). Reelin stimulation increased the phosphorylation of Dab1 (Fig. $1 F$, lane $4, G$ ) compared with control stimulation (Fig. $1 F$, lane $3, G)$. These results indicated that all of the major canonical components of the Reelin signaling pathway exist in OPCs, as in neurons.

We next investigated the effect of Reelin on the proliferation of OPCs. Rat OPCs were incubated with or without Reelin for 24 $\mathrm{h}$, and BrdU was added in the last $5 \mathrm{~h}$. They were then fixed and immunostained with anti-BrdU and anti-Olig2 antibodies (Fig. $2 A)$. We found that Reelin reduced the percentage of Olig $2^{+}$cells that were BrdU-labeled by $\sim 20 \%$, whereas $\mathrm{KA}_{2}$-Reelin had no effect (Fig. 2A,B). Thus, Reelin suppressed the proliferation of OPCs in vitro. We then tested whether this effect of Reelin is dependent on Dab1. We cultured primary OPCs from WT (Fig. $2 C$, upper panels) or Dab1 $1^{\text {yot/yot }}$ (Fig. 2C, lower panels) mice and incubated them with Reelin and BrdU, as described above. Reelin suppressed the proliferation of the OPCs derived from WT mice (Fig. 2C, upper panels, $D$ ), but had no effect on those derived from $D a b 1^{\text {yot/yot }}$ mice (Fig. $2 C$, lower panels, E). These data demonstrated that Reelin suppressed the proliferation of OPCs by binding to Reelin receptors and requires signal transduction via Dab1.

We next aimed to determine how Reelin was able to reduce the proliferation of OPCs. We cultured rat OPCs with or without Reelin and performed qRT-PCR analysis for 14 candidate genes 
reported to be involved in OPC development (Table 2; Winkler et al., 2018; Emery and Lu, 2015; Bergles and Richardson, 2016). However, although there were a few genes whose expression tended to change by Reelin stimulation, none of them showed statistically significant change. Thus, Reelin-Dab1 signaling may affect the proliferation of OPCs by a mechanism not yet known well.

\section{Reelin regulates the migration of OPCs in a Dab1-dependent manner in vitro}

Reelin is essential for the proper migration of neurons during development (Hirota and Nakajima, 2017). We investigated whether Reelin affects the migration of OPCs in vitro by using a Boyden chamber (Fig. 3A). Rat OPCs were plated on the PLL-coated filters of the culture inserts and allowed to migrate into the lower wells through $8-\mu \mathrm{m}$ pores. Reelin was placed either in the inserts or the lower well of the chamber (Fig. $3 A$, middle and right). After a 24-h incubation, we counted the number of $\mathrm{Olig} 2^{+} \mathrm{PDGFR} \alpha^{+}$cells that had migrated to the lower (chamber) side of the insert. When Reelin was present in the upper side, the number of migrated OPCs significantly increased (Fig. 3B, middle panel, $C$, black bar). In contrast, when Reelin was present on the lower side, the number of migrated OPCs decreased (Fig. $3 B$, right panel, $C$, gray bar). We confirmed that the Reelin gradient was maintained during the experiment, although a small amount of Reelin protein was detected in the section that had not initially contained Reelin (Fig. 3D). These results indicated that OPCs migrate toward the side where the concentration of Reelin is lower and suggest that Reelin might act as a repellant molecule for the migration of OPCs.

We next examined whether this effect of Reelin is dependent on Dab1. We cultured primary OPCs from WT (Fig. 3E, upper panels) or Dab1 $1^{\text {yot/yot }}$ (Fig. 3E, lower panels) mice and incubated them with or without Reelin in a Boyden chamber as described above. Similar results were observed in OPCs derived from WT mice, as in OPCs derived from rats (Fig. $3 F$ ). When Reelin was present in the upper side, the number of migrated OPCs increased (Fig. 3E, upper-middle panel, $F$, black bar), whereas when Reelin was present on the lower side, the number of migrated OPCs significantly decreased (Fig. $3 E$, upper-right panel, $F$, gray bar). However, Reelin had no effect on the migration of OPCs derived from $D a b 1^{\text {yot/yot }}$ mice (Fig.
A

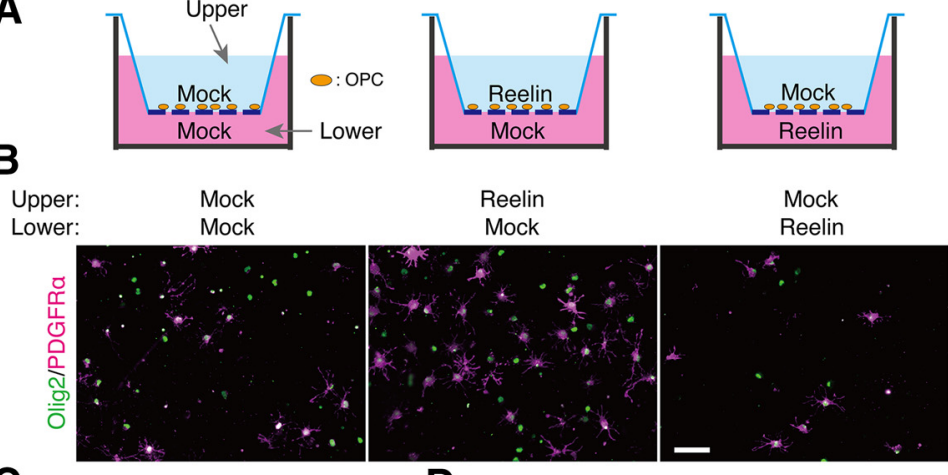

C

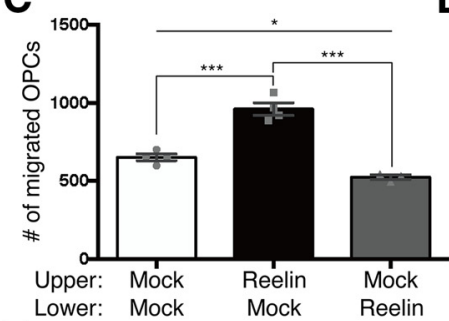

D

Upper (U) : Mock Reelin Mock Lower (L) : Mock mock Reelin

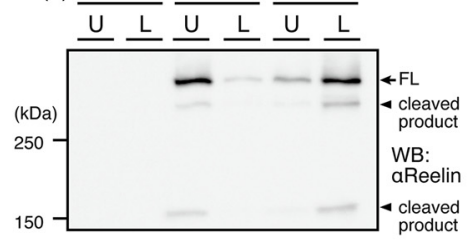

E

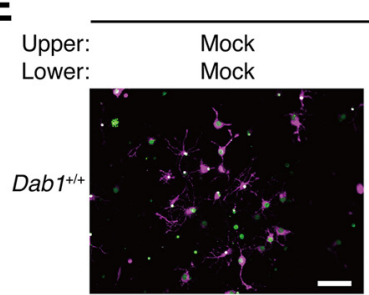

Olig2/PDGFRa
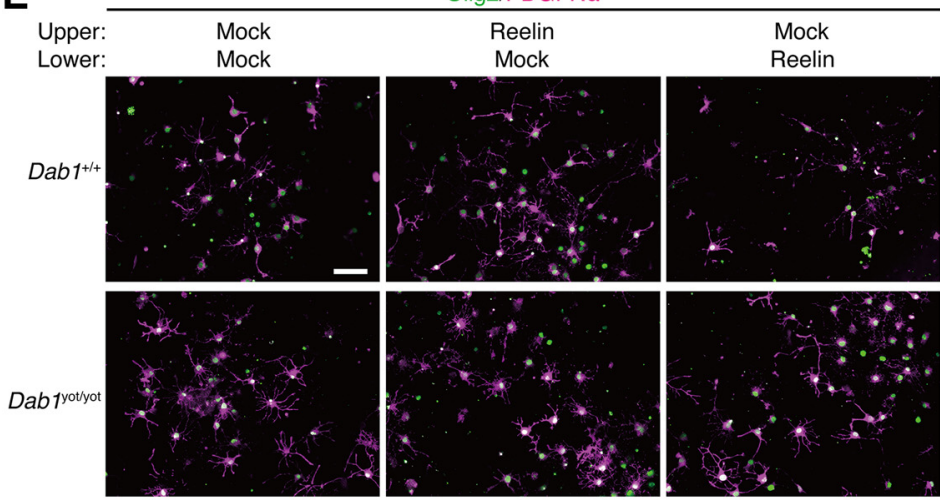

$\mathbf{F}$
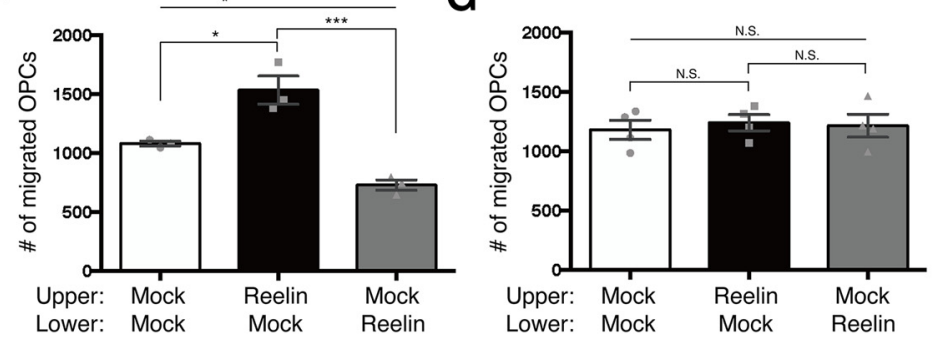

Figure 3. Reelin affects the migration of OPCS in a Dab1-dependent manner in vitro. $\boldsymbol{A}$, Schematic diagram of the Boyden chamber assay. OPCs were cultured with vehicle only (Mock) or WT-Reelin (Reelin) in the upper or lower wells for $24 \mathrm{~h} . \boldsymbol{B}$, Rat OPCs were incubated for $24 \mathrm{~h}$ with mock or Reelin as described above the images of the Boyden chamber. Cells that migrated into the lower wells through the 8- $\mu$ m pores of the membrane were immunostained for Olig2 (green) and PDGFR $\alpha$ (magenta). Scale bar: $50 \mu \mathrm{m}$. C, The number of PDGFR $\alpha^{+}$Olig2 ${ }^{+}$OPCs that migrated into the lower side of the membrane was counted. The culture media in the inserts and plates are indicated below the graph. The data were analyzed using one-way ANOVA $\left(F_{(2,9)}=54.89, p<0.0001\right)$ followed by Tukey-Kramer post hoc test; ${ }^{*} p<0.05$ and ${ }^{* * *} p<0.001 . N=4$. D, WB analysis of the culture medium placed in the inserts (upper wells, $\mathrm{U}$ ) or the lower wells $(\mathrm{L})$ using anti-Reelin antibody. The culture media in the inserts and plates are indicated below the figure. Positions of molecular mass markers $(\mathrm{kDa})$ are shown on the left of the panel. FL: full-length Reelin. $\boldsymbol{E}, \mathrm{OPC}$ derived from Dab1 $1^{+/+}$mice (upper panels) or Dab1 $1^{\text {yot/yot }}$ mice (lower panels) were incubated for $24 \mathrm{~h}$ with mock or Reelin as described above the images of the Boyden chamber for $24 \mathrm{~h}$. The cells that migrated into the lower wells through the 8- $\mu \mathrm{m}$ pores of the membrane were immunostained for Olig2 (green) and PDGFR $\alpha$ (magenta). Scale bar: $50 \mu \mathrm{m}$. $\boldsymbol{F}$, The number of PDGFR $\alpha^{+}$0lig2 ${ }^{+} \mathrm{OPCs}$ derived from Dab1 ${ }^{+/+}$mice that migrated into the lower side of the membrane was counted. The culture media in the inserts and plates are indicated below the graph. The data were analyzed using one-way ANOVA $\left(F_{(2,6)}=29.86, p=0.0008\right)$ followed by Tukey-Kramer post hoc test; * $p<0.05$ and ${ }^{* * *} p<0.001 . N=3$. G, The number of PDGFR $\alpha^{+} 0$ lig2 ${ }^{+} \mathrm{OPCS}$ derived from Dab $1^{\text {yot/yot }}$ mice that migrated into the lower side of the membrane was counted. The culture media in the inserts and plates are indicated below the graph. The data were analyzed using one-way ANOVA $\left(F_{(2,9)}=0.1285, p=0.8810\right)$ followed by Tukey-Kramer post hoc test. N.S., not significant. $N=4$. 

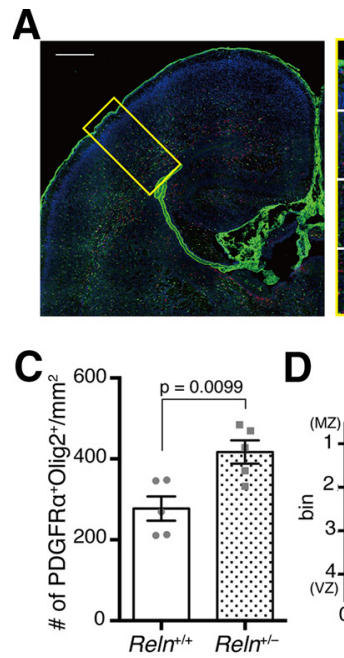

D
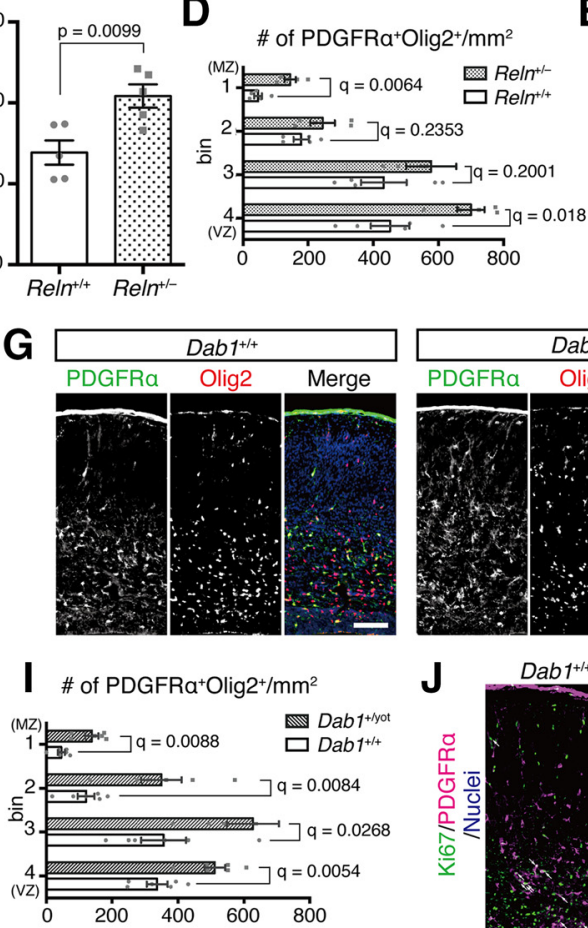
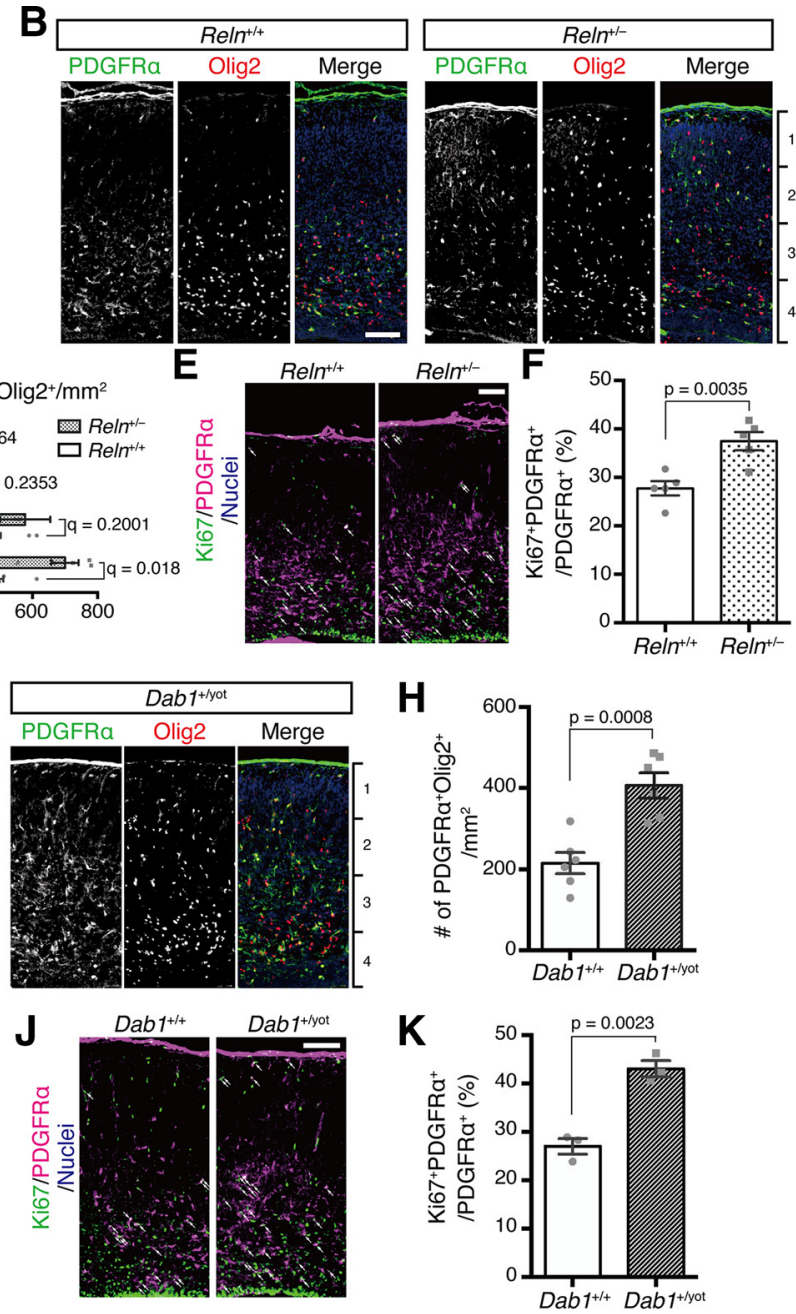

Figure 4. The number and distribution of OPCS are altered in Reelin heterozygote-deficient and Dab1 heterozygote-deficient mutant mice. $A$, Coronal sections of mouse brain at E18.5 were immunostained with antibodies against PDGFR $\alpha$ (green) and Olig2 (red). Nuclei were stained using Hoechst 33342. The magnified image of the part of primary somatosensory cortex (yellow box, left) is shown on the right. Primary somatosensory cortex was divided into four bins from the VZ to the MZ. Scale bar: $500 \mu \mathrm{m}$. $\boldsymbol{B}$, Coronal sections of the primary somatosensory cortex of Reln ${ }^{+/+}$and Reln ${ }^{+/}$mice at E18.5 were immunostained with antibodies against PDGFR $\alpha$ (green) and Olig2 (red). Nuclei were stained using Hoechst 33342. Scale bar: $100 \mu \mathrm{m}$. C, D, Quantification of the density of OPCs in the primary somatosensory cortex (C) and in each of four equal-size bins (D). The data were analyzed using a two-tailed Student's $t$ test and FDR-adjusted $q$ values are shown. $n=5$ each. $E$, Coronal sections of the primary somatosensory cortex of Reln ${ }^{+/+}$ and $R e / n^{+1-}$ mice at E18.5 were immunostained with antibodies against Ki67 (green) and PDGFR $\alpha$ (red). Nuclei were stained using Hoechst 33342 . Arrows indicate Ki67 ${ }^{+}$PDGFR $\alpha^{+}$cells. Scale bar: $100 \mu \mathrm{m}$. $\boldsymbol{F}$, Quantification of the percentage of Ki67 ${ }^{+}$PDGFR $\alpha^{+}$cells of total PDGFR $\alpha^{+}$cells. The data were analyzed using a two-tailed Student's $t$ test. $n=5$ each. $G$, Coronal sections of the primary somatosensory cortex of $D a b 1^{+/+}$and $D a b 1^{+/ y o t}$ mice at E18.5 were immunostained with antibodies against PDGFR $\alpha$ (green) and Olig2 (red). Nuclei were stained using Hoechst 33342. Scale bar: $100 \mu \mathrm{m}$. $\boldsymbol{H}, \mathbf{I}$, Quantification of the density of OPCs in the primary somatosensory cortex $(\boldsymbol{H})$ and in each of four equal-size bins $(\boldsymbol{I})$. The data were analyzed using a two-tailed Student's $t$ test, and FDR-adjusted $q$ values are shown. $n=6$ each. $J$, Coronal sections of

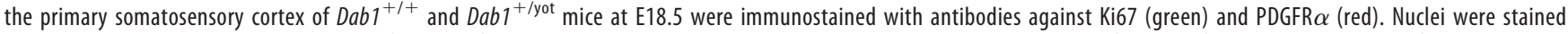
using Hoechst 33342. Arrows indicate Ki67 ${ }^{+}$PDGFR $\alpha^{+}$cells. Scale bar: $100 \mu \mathrm{m}$. $\boldsymbol{K}$, Quantification of the percentage of Ki67 ${ }^{+}$PDGFR $\alpha^{+}$cells of total PDGFR $\alpha^{+}$cells. The data were analyzed using a two-tailed Student's $t$ test. $n=3$ each.

3E, lower panels, $G)$. Therefore, Reelin affects the migration of OPCs in a Dab1-dependent manner and might act as a repellant.

OPC number and distribution are affected in the late embryonic neocortex of $\operatorname{Reln}^{+/-}, \mathrm{Dab1}^{+/ y o t}$, and $\mathrm{Vldlr}^{-/-}$mice We next investigated whether the Reelin-Dab1 signaling is involved in the regulation of OPC number or distribution in vivo. Because neocortical structures were severely disrupted in $\mathrm{Reln}^{-1-}$ and Dab1 ${ }^{\text {yot/yot }}$ mice, we used $\mathrm{Reln}^{+/-}$and Dab1 ${ }^{+/ \text {yot }}$ mice, whose neocortical structures are almost normal. We immunostained the neocortex of $\operatorname{Reln}^{+/-}$(Fig. $4 B$ ) and Dab1 ${ }^{+/ \text {yot }}$ (Fig. 4G) mice at E18.5 with anti-PDGFR $\alpha$ and anti-Olig2 antibodies and counted the numbers of PDGFR $\alpha^{+} \mathrm{Olig} 2^{+}$cells (Fig.
$4 C, H)$. We found that the density of OPCs in the neocortex dramatically increased in these mice (approximately a 50\% increase in $\operatorname{Reln}^{+/-}$mice and a $90 \%$ increase in $D a b 1^{+/ \text {yot }}$ mice; Fig. $4 C$, $H$ ). In the Reln ${ }^{+/-}$(Fig. 4B) and Dab1 ${ }^{+/ \text {yot }}$ (Fig. 4G) mice, the distribution of OPCs markedly shifted toward the superficial layer where Reelin is expressed and secreted. For quantification, we divided the neocortex into four bins from the VZ to the MZ and counted the number of OPCs in each bin. The change was more prominent in the superficial region than in the deep one (Fig. 4D,I). The PDGFR $\alpha$ immunofluorescent signal was also much stronger in $\mathrm{Reln}^{+/-}$and $\mathrm{Dab1}^{+/ \text {yot }}$ mice than in control mice (Fig. 4B,G). Because PDGF signaling via PDGFR $\alpha$ is the major mitogenic factor for OPCs (Calver et al., 1998; Fruttiger et al., 1999), we next examined whether Reelin-Dab1 signaling 

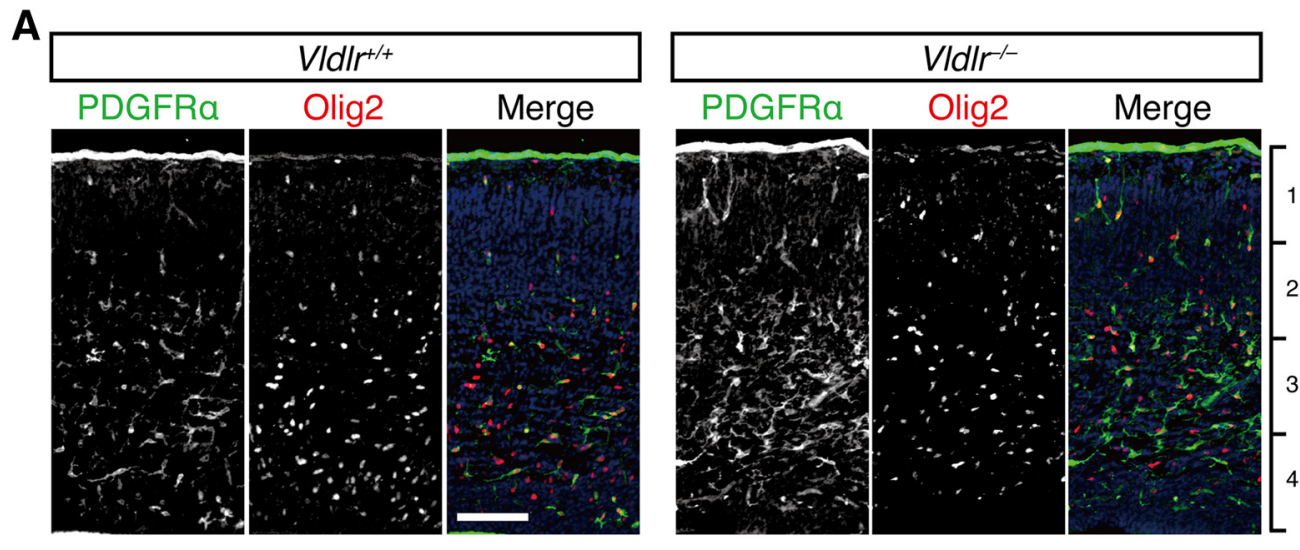
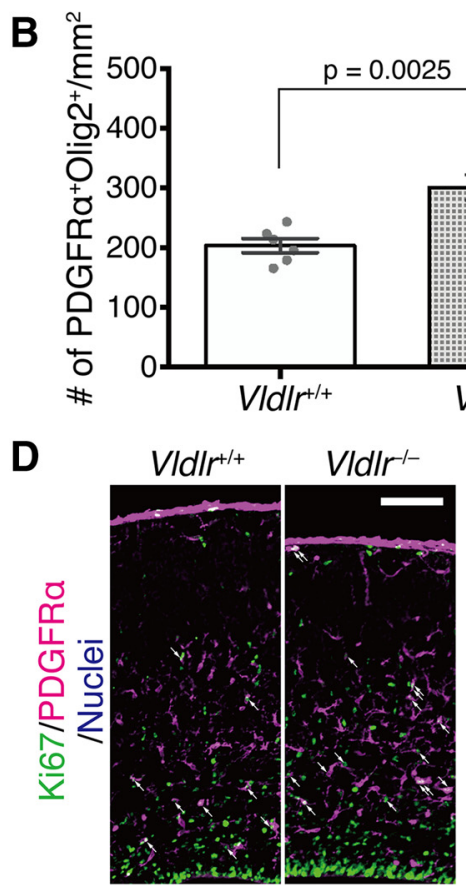

\section{C \# of PDGFRa + Olig2 $+/ \mathrm{mm}^{2}$}

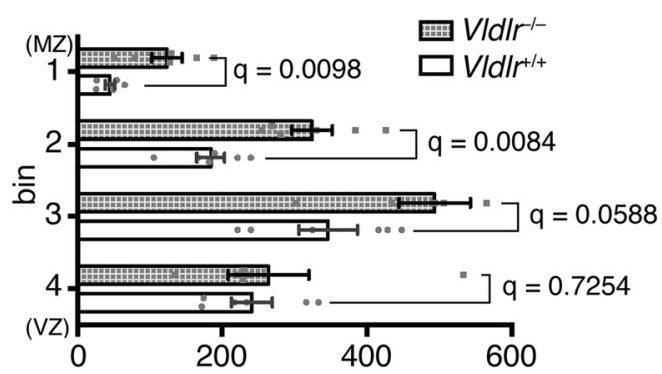

E

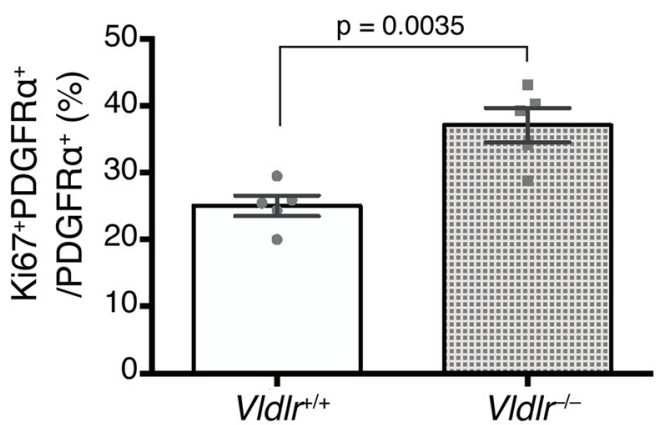

Figure 5. The number and distribution of OPCs are altered in VLDLR-deficient mice. A, Coronal sections of the primary somatosensory cortex of VIdlr ${ }^{+/+}$and VIdlr ${ }^{-/-}$mice at E18.5 were immunostained with antibodies against PDGFR $\alpha$ (green) and Olig2 (red). Nuclei were stained using Hoechst 33342. Scale bar: $100 \mu \mathrm{m} . \boldsymbol{B}, \boldsymbol{C}$, Quantification of the density of OPCs in the primary somatosensory cortex $(\boldsymbol{B})$ and in each of four equal-size bins (C). The data were analyzed using a two-tailed Student's $t$ test, and FDR-adjusted $q$ values are shown. $n=6$ each. $\boldsymbol{D}$, Coronal sections of the primary somatosensory cortex of $V / d l r^{+/+}$and VIdlr ${ }^{-1-}$ mice at E18.5 were immunostained with antibodies against Ki67 (green) and PDGFR $\alpha$ (red). Nuclei were stained using Hoechst 33342. Arrows indicate Ki67 ${ }^{+}$PDGFR $\alpha^{+}$cells. Scale bar: $100 \mu \mathrm{m}$. E, Quantification of the percentage of Ki67 ${ }^{+}$PDGFR $\alpha^{+}$cells of total PDGFR $\alpha^{+}$cells. The data were analyzed using a two-tailed Student's $t$ test. $n=5$ each.

affects the proliferation of OPCs in the neocortex. We immunostained the neocortical slices with anti-Ki67 and anti-PDGFR $\alpha$ antibodies (Fig. 4E,J). The percentages of $\mathrm{Ki} 67^{+} \mathrm{PDGFR} \alpha^{+}$ OPCs were increased in $\mathrm{Reln}^{+/-}$(Fig. $4 F$ ) and $\mathrm{Dab1}^{+/ \text {yot }}$ (Fig. $4 K)$ mice by $\sim 1.4$-fold compared with control mice.

We next analyzed VLDLR knock-out $\left(\mathrm{Vldlr}^{-/-}\right)$mice (Fig. $5 \mathrm{~A}$ ), whose layer structure of the neocortex is essentially maintained except for a mild abnormality in the MZ (Hack et al., 2007; Hirota and Nakajima, 2020). The density of OPCs in the neocortex was increased in the $\mathrm{Vldlr}^{-/-}$mice by $\sim 50 \%$ at E18.5 (Fig. 5B). The distribution of OPCs shifted toward the superficial position because the fold change was more prominent in the superficial region (Fig. 5C). Moreover, the percentage of Ki67 ${ }^{+}$PDGFR $\alpha^{+}$OPCs increased in the Vldlr $^{-/-}$mice (Fig. 5D,E). Altogether, these data suggested that the diminished Reelin-Dab1 signaling increases the proliferation of OPCs and that Reelin acts as a repellant for the radial migration of OPCs in vivo.
The regulation of Reelin function by its proteolysis is involved in the normal development of OPCs

Reelin is specifically cleaved by ADAMTS- 3 in the embryonic neocortex (Ogino et al., 2017). The Reelin-Dab1 signaling is upregulated in Adamts $3^{-/-}$mice, without affecting the layer structure (Ogino et al., 2017). In addition, we recently established cleavage-resistant Reelin knock-in ( $\left.\operatorname{Reln}^{P A-D V / P A-D V}\right)$ mouse (Okugawa et al., 2020). Reelin signaling is augmented in this mouse, but its neocortical layer structure is largely normal (Okugawa et al., 2020). We analyzed the development of OPCs in these mice.

The number of PDGFR $\alpha^{+}$Olig2 ${ }^{+}$OPCs in the neocortex was significantly decreased in both Adamts $3^{-/}$(Fig. 6A,B) and $\operatorname{Reln}^{P A-D V / P A-D V}$ (Fig. 6F,G) mice compared with their control mice. The OPC distribution tended to shift toward the VZ in Adamts $3^{-/-}$(Fig. 6C) and Reln ${ }^{P A-D V / P A-D V}$ (Fig. 6H) mice. The immunofluorescent signal of PDGFR $\alpha$ was markedly weaker in 
A
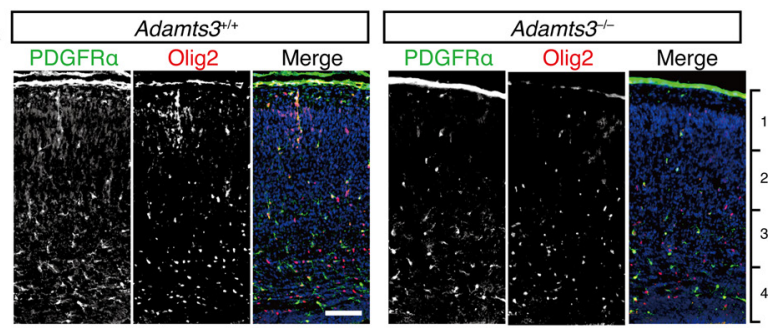

B

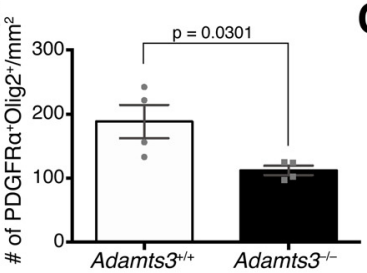

D

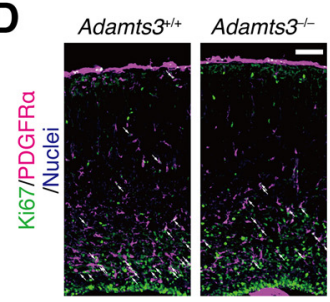

$\mathbf{F}$
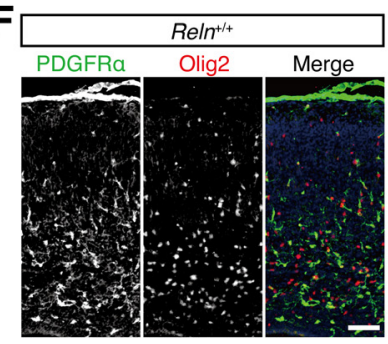

G

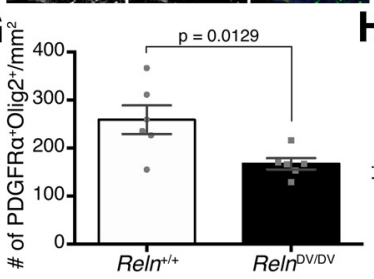

$\mathrm{H}$

$\mathrm{E}$
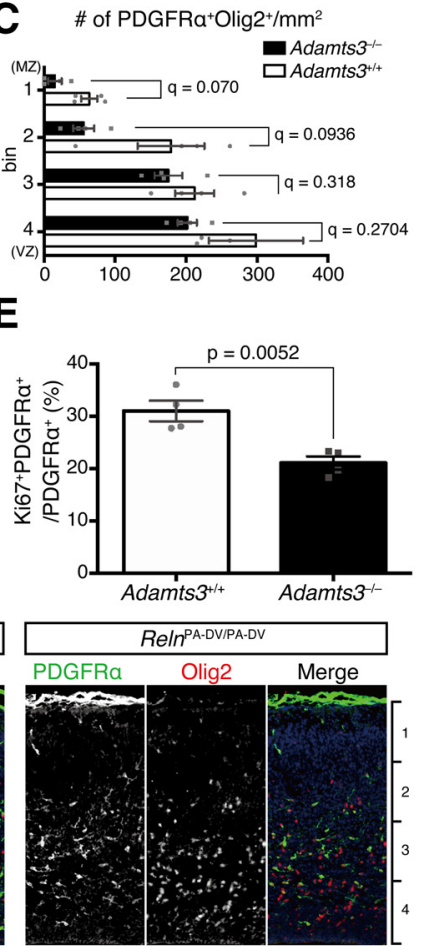

\# of PDGFRa ${ }^{+} \mathrm{Olig}^{+} / \mathrm{mm}^{2}$

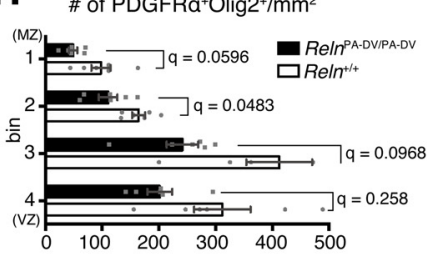

J
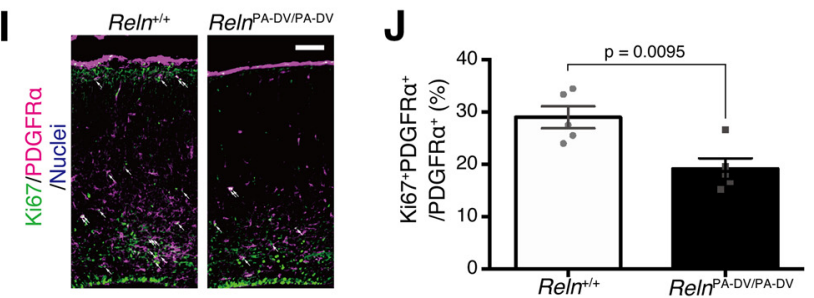

Figure 6. The number and distribution of OPCS are altered in mice with abrogated Reelin cleavage. $A$, Coronal sections of the primary somatosensory cortex of Adamts $3^{+/+}$and Adamts $3^{-/-}$mice at E18.5 were immunostained with antibodies against PDGFR $\alpha$ (green) and Olig2 (red). Nuclei were stained using Hoechst 33342. Scale bar: $100 \mu \mathrm{m}$. B, C, Quantification of the density of OPCs in the primary somatosensory cortex $(\boldsymbol{B})$ and in each of four equal-size bins (C). The data were analyzed using a two-tailed Student's $t$ test, and FDR-adjusted $q$ values are shown. $n=4$ each. $D$, Coronal sections of the primary somatosensory cortex of Adamts ${ }^{+/+}$and Adamts $3^{-/}$mice at E18.5 were immunostained with antibodies against Ki67 (green) and PDGFR $\alpha$ (red). Nuclei were stained using Hoechst 33342. Arrows indicate $\mathrm{Ki}_{67}{ }^{+}$PDGFR $\alpha^{+}$cells. Scale bar: $100 \mu \mathrm{m}$. $\boldsymbol{E}$, Quantification of the percentage of $\mathrm{Ki}^{+} 7^{+} \mathrm{PDGFR} \alpha^{+}$cells of total PDGFR $\alpha^{+}$cells. The data were analyzed using a twotailed Student's $t$ test. $n=4$ each. $\boldsymbol{F}$, Coronal sections of the primary somatosensory cortex of $R e l n^{+/+}$and $R e l n^{P A-D V / P A-D V}$ mice at E18.5 were immunostained with antibodies against PDGFR $\alpha$ (green) and Olig2 (red). Nuclei were stained using Hoechst 33342. Scale bar:
Adamts $3^{-/-}$and Reln ${ }^{P A-D V / P A-D V}$ mice compared with control mice (Fig. 6A,F). Furthermore, the percentage of $\mathrm{Ki}^{+} 7^{+}$ PDGFR $\alpha^{+}$OPCs was decreased in these mice (Fig. 6D,E,I,J). These data were essentially the opposite of those obtained in $\operatorname{Reln}^{+/-}, \mathrm{Dab1}^{+/ \mathrm{yot}}$ (Fig. 4), and $\mathrm{Vldlr}^{-/}$(Fig. 5) mice. Thus, they further support the theory that Reelin suppresses the proliferation of OPCs in vivo and that Reelin acts as a repellant in their radial distribution. They also indicate that modulation of Reelin function by specific proteolysis plays a role in normal OPC development.

Reelin-Dab1 signaling has little effect on the number and distribution of OPCs in the postnatal brain

Finally, we investigated the effect of Reelin-Dab1 signaling on the OPCs in the postnatal neocortex. In the neocortex of Reln ${ }^{+/-}$ mice at P2, the number and position of PDGFR $\alpha^{+}$Olig2 ${ }^{+}$cells were not affected (Fig. $7 A-C$ ). In the neocortex of $D a b 1^{+/ y o t}$ mice at P2, the total number of PDGFR $\alpha^{+} \mathrm{Olig} 2^{+}$cells was slightly increased (Fig. 7E). The radial distribution of OPCs was indistinguishable between $D a b 1^{+/+}$and $D a b 1^{+/ \text {yot }}$ mice (Fig. $7 F)$. These results suggest that the contribution of Reelin-Dab1 signaling to the number and radial distribution of the OPCs in neocortex becomes smaller as the brain develops. Alternatively, there may be a compensatory mechanism(s) that tightly regulates the OPCs' number and distribution.

\section{Discussion}

In this study, we showed that Reelin suppresses the proliferation and affects the migration of OPCs both in vitro and in vivo, and that the radial distribution of OPCs is affected in the late embryonic neocortex of mice with diminished or augmented ReelinDab1 signaling. This is the first demonstration of the direct effect of Reelin on OPCs, and the first identification of the molecule that regulates their radial distribution in the late embryonic stage.

Numerous studies have examined the mechanisms regulating the development of OPCs in the spinal cord or optic nerve or in vitro, and several secreted molecules have been identified as regulators in their respective systems (Mitew et al., 2014; Emery and Lu, 2015; Bergles and Richardson, 2016). However, few reports have explored the molecular mechanisms underlying OPC development in the neocortex during development (Choe et al., 2014; Tsai et al., 2016). Moreover, no cue has been identified to regulate the radial distribution of OPC in the neocortex. We believe that Reelin is the first secreted molecule found to play a role in the radial distributions of OPCs in the developing neocortex.

Reelin plays pivotal roles in neuronal development and function (Hirota and Nakajima, 2017; Wasser and Herz, 2017). However, analysis of the importance of Reelin in OPCs has been scarce. In this study, we showed that Reelin suppresses the proliferation of OPCs in vitro (Fig. 2) and that both the total number of OPCs and the percentage of $\mathrm{Ki} 67^{+} \mathrm{PDGFR} \alpha^{+}$OPCs were

$100 \mu \mathrm{m} . \mathbf{G}, \boldsymbol{H}$, Quantification of the density of OPCs in the primary somatosensory cortex (G) and in each of four equal-size bins $(\boldsymbol{H})$. The data were analyzed using a two-tailed Student's $t$ test, and FDR-adjusted $q$ values are shown. $n=6$ each. $I$, Coronal sections of the primary somatosensory cortex of Reln ${ }^{+/+}$and Reln ${ }^{P A-D V / P A-D V}$ mice at E18.5 were immunostained with antibodies against Ki67 (green) and PDGFR $\alpha$ (red). Nuclei were stained using Hoechst 33342. Arrows indicate $\mathrm{Ki} 67^{+} \mathrm{PDGFR} \alpha^{+}$cells. Scale bar: $100 \mu \mathrm{m}$. J, Quantification of $\mathrm{Ki}^{+} 7^{+}$PDGFR $\alpha^{+}$cells of total PDGFR $\alpha^{+}$cells. The data were analyzed using a two-tailed Student's $t$ test. $n=5$ each. 
increased in the late embryonic neocortex of $\operatorname{Reln}^{+/-}, \mathrm{Dab1} 1^{+/ \text {yot }}$, and $\mathrm{Vldlr}^{-/-}$mice compared with the control (Figs. 4, 5). In contrast, they were decreased in the neocortex of Adamts $3^{-/}$ and $\operatorname{Reln}{ }^{P A-D V / P A-D V}$ mice with augmented Reelin-Dab1 signaling (Fig. 6). These results suggest that Reelin directly regulates the number of OPCs. We also showed for the first time that Reelin acts as a regulatory cue for OPC distribution in the late embryonic neocortex (Figs. 46). In an in vitro assay, Reelin stimulated the migration of OPCs toward the lowReelin side in a Dab1-dependent manner (Fig. 3). In the developing neocortex, OLs show graded distribution from the white matter and deep cortical layers to the superficial cortical layers (Tan et al., 2009). This gradient is disrupted in mice with attenuated Reelin signaling (i.e., $\operatorname{Reln}^{+/-}$, $D a b 1^{+/ \text {yot }}$, and $V l d l r^{-1-}$ mice; Figs. 4, 5) and in mice with augmented Reelin signaling (i.e., Adamts $3^{-/-}$and Reln ${ }^{P A-D V / P A-D V}$ mice; Fig. 6). These results can be explained most simply by a model in which Reelin is a repellant and/or in which proliferation of OPCs are more suppressed near the superficial layer where Reelinexpressing Cajal-Retzius cells are found (Fig. 8). Taken together, we suggest that Reelin regulates the number and the radial distribution of OPCs in the late embryonic neocortex. It is also indicated that the specific proteolysis of Reelin plays a significant role in the OPC development.

The immunofluorescent signals of PDGFR $\alpha$ were stronger in the neocortex of $\mathrm{Reln}^{+/-}, \mathrm{Dabl}^{+/ \text {yot }}$, and $\mathrm{Vldlr}^{-/-}$mice, than in control mice (Figs. $4 B, G, 5 A$ ). In contrast, in the neocortex of Adamts $3^{-/-}$ mice and Reln ${ }^{P A-D V / P A-D V}$ mice, the $\operatorname{PDGFR} \alpha$ levels were weaker than that in control mice (Fig. 6A,F). These results suggest that Reelin decreases the expression of PDGFR $\alpha$. PDGF is mitogenic (Calver et al., 1998; Fruttiger et al., 1999) and motogenic (Wolswijk and Noble, 1992; Miyamoto et al., 2008) for OPCs. Thus, it is possible that the downregulation of PDGFR $\alpha$ by Reelin contributes to the effect on proliferation or migration of OPCs. However, Reelin did not affect the expression of PDGFR $\alpha$ mRNA (Table 2) or its protein levels (data not shown) in OPCs in vitro. There may be other factors that cooperate with Reelin to decrease the expression of PDGFR $\alpha$ in vivo.

Finally, the effect of the heterozygous deficiency of Dab1 is more severe than that of Reelin (Fig. 4). The reason for this difference is unknown, but it is possible that Dab1 plays a role in another pathway. For example, Dab1 is known to be involved in the Notch pathways (Hashimoto-Torii et al., 2008), which is one of the critical determinants of OPC differentiation (Ravanelli et
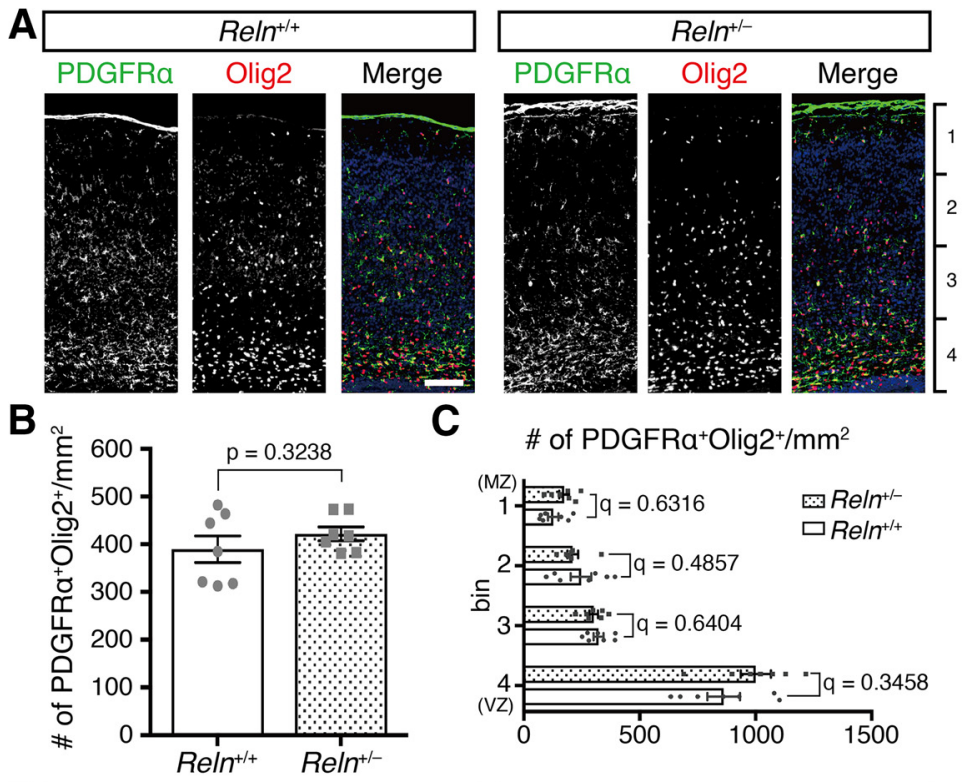

\# of PDGFRa ${ }^{+} \mathrm{Olig2}^{+} / \mathrm{mm}^{2}$
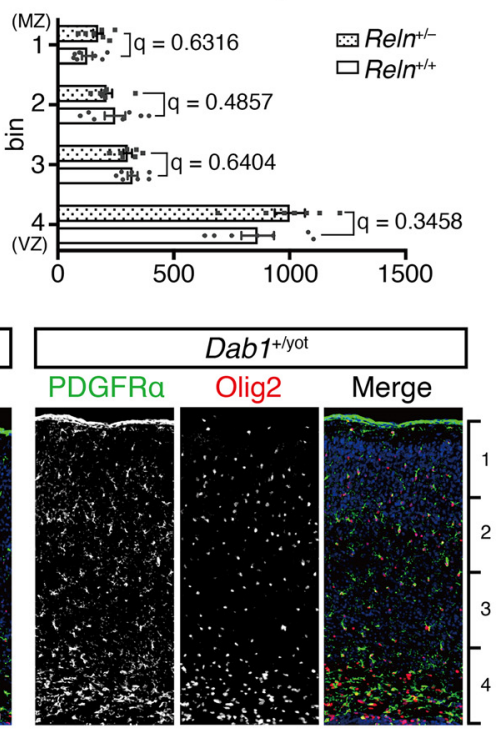

$\mathbf{E}$

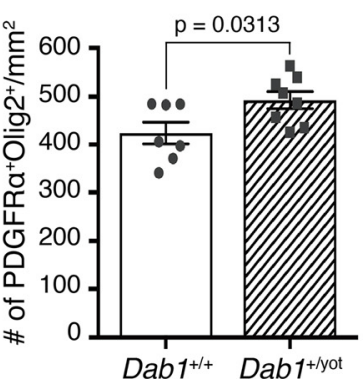

$\mathbf{F}$
\# of PDGFRa ${ }^{+} \mathrm{Olig}^{+} / \mathrm{mm}^{2}$

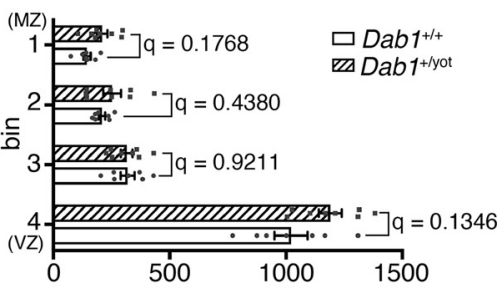

Figure 7. The effect of Reelin-Dab1 signaling on the number and distribution of OPCs becomes small in the postnatal brain. $A$, Coronal sections of the primary somatosensory cortex of $\mathrm{Reln}^{+/+}$and $\mathrm{Reln}^{+/-}$mice at P2 were immunostained with antibodies against PDGFR $\alpha$ (green) and 0lig2 (red). Nuclei were stained using Hoechst 33342. Scale bar: $100 \mu \mathrm{m}$. B, C, Quantification of the density of OPCs in the primary somatosensory cortex $(\boldsymbol{B})$ and in each of four equal-size bins (C). The data were analyzed using a two-tailed Student's $t$ test, and FDR-adjusted $q$ values are shown. $n=7$ each. $\boldsymbol{D}$, Coronal sections of the primary somatosensory cortex of $\mathrm{Dab}^{+/+}$and $\mathrm{Dab}^{+/ \text {yot }}$ mice at P2 were immunostained with antibodies against PDGFR $\alpha$ (green) and Olig2 (red). Nuclei were stained using Hoechst 33342. Scale bar: $100 \mu \mathrm{m} . \boldsymbol{E}, \boldsymbol{F}$, Quantification of the density of OPCs in the primary somatosensory cortex $(\boldsymbol{E})$ and in each of four equal-size bins $(\boldsymbol{F})$. The data were analyzed using a twotailed Student's $t$ test, and FDR-adjusted $q$ values are shown. $n=7$ and 8 for $D a b 1^{+/+}$and $D a b 1^{+/ \text {yot }}$ mice, respectively.

al., 2018; Ge et al., 2019). Clarification of the detailed underlying mechanism by which Reelin and Dab1 affects OPCs will be a next challenge.

How does Reelin regulate the number and the distribution of OPCs in a site-specific manner in the brain? One possible scenario is that Reelin is distributed as a gradient through the neocortex. In the zebrafish optic tectum, the graded concentration of Reelin is stabilized by a heparin sulfate proteoglycans gradient, which is required for synaptic lamination in the visual system (Di Donato et al., 2018). Kupferman and colleagues suggested that, for hippocampal CA1 and neocortical Layer V pyramidal 


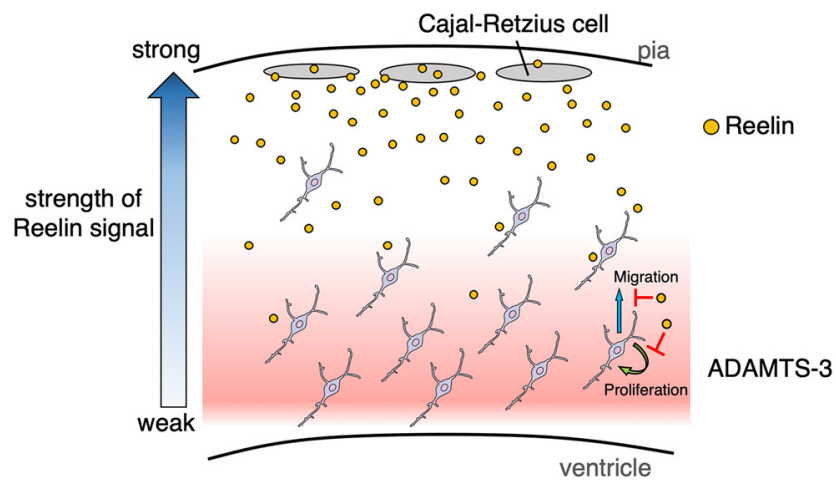

Figure 8. Schematic model how Reelin signaling affects OPCs' development in the late embryonic neocortex. Reelin (yellow) is secreted from Cajal-Retzius (gray oval) cells located in the MZ and diffuses toward the VZ. ADAMTS-3 is relatively strongly expressed in the deep layer of the neocortex (red). Thus, it can be speculated that the strength of Reelin signaling exists in a graded manner. The proliferation and distribution of OPCs are negatively regulated by Reelin signaling.

neurons, Reelin signaling is required for distal dendritic localization and surface expression of ion channels (Kupferman et al., 2014; but see also Meseke et al., 2018). Reelin is cleaved and inactivated by ADAMTS-3, which is expressed mainly by the deep layer neurons (Ogino et al., 2017). Because Reelin is expressed in the MZ, the strength of Reelin signaling might be regulated in a graded manner from the superficial layer to the deep layer of the neocortex. In the late embryonic neocortex, OPCs are generated from the LV and proliferate and migrate toward the superficial layers. Thus, we suspect that OPCs proliferate and migrate actively in the deep layers where Reelin signaling is weak and, when they reach the superficial region, stop their proliferation and prefer not to approach the Reelin-expressing Cajal-Retzius cells (Fig. 8).

OPCs express both Reelin and its receptors (Siebert and Osterhout, 2011; Fig. 1). In the adult brain, the number of OPCs is maintained constant by unknown mechanisms (Bergles and Richardson, 2016). Interestingly, each OPC has its own "territory" and the OPCs never overlap with each other in the neocortex (Bergles and Richardson, 2016), mainly by self-repulsion (Hughes et al., 2013). The mechanism or cue molecule(s) involved in this event remains unknown, but one possibility is that Reelin secreted by OPCs might function in a paracrine fashion. Future studies will be important to clarify whether Reelin derived from OPCs truly plays a role in OPC development.

Alarge population of OPCs persists into adulthood. Reelin plays important roles in synaptic plasticity, memory formation, and learning in the adult brain, and myelination contributes to these processes (Fields, 2008). Reelin is involved in the pathogenesis of many neurologic diseases including schizophrenia (Folsom and Fatemi, 2013; Ishii et al., 2016), depression (Caruncho et al., 2016), and multiple sclerosis (Talebian et al., 2019). These diseases often show defects in OPC development or/and myelin (Fields, 2008; Birey et al., 2017; Chen et al., 2018). In the peripheral nervous system, Reelin is transiently expressed after nerve crush (Panteri et al., 2006), and Reelin-deficient mice show defects in the regeneration of the peripheral nervous system (Lorenzetto et al., 2008). Moreover, sciatic nerve injury increases the expression of ApoER2 and Reelin, and Reelin is involved in the migration of Schwann cells (Pasten et al., 2015). It will be of interest to inspect the effects of Reelin on OPC development in the adult brain, particularly under pathologic conditions.

\section{References}

Arai K, Lo EH (2009) An oligovascular niche: cerebral endothelial cells promote the survival and proliferation of oligodendrocyte precursor cells. J Neurosci 29:4351-4355.

Benjamini Y, Hochberg Y (1995) Controlling the false discovery rate: a practical and powerful approach to multiple testing. J R Statist Soc B 57:289300 .

Bergles DE, Richardson WD (2016) Oligodendrocyte development and plasticity. Cold Spring Harb Perspect Biol 8:a020453.

Birey F, Kokkosis AG, Aguirre A (2017) Oligodendroglia-lineage cells in brain plasticity, homeostasis and psychiatric disorders. Curr Opin Neurobiol 47:93-103.

Bradley A, Anastassiadis K, Ayadi A, Battey JF, Bell C, Birling MC, Bottomley J, Brown SD, Bürger A, Bult CJ, Bushell W, Collins FS, Desaintes C, Doe B, Economides A, Eppig JT, Finnell RH, Fletcher C, Fray M, Frendewey D, et al. (2012) The mammalian gene function resource: the international knockout mouse consortium. Mamm Genome 23:580-586.

Calver AR, Hall AC, Yu WP, Walsh FS, Heath JK, Betsholtz C, Richardson WD (1998) Oligodendrocyte population dynamics and the role of PDGF in vivo. Neuron 20:869-882.

Caruncho HJ, Brymer K, Romay-Tallón R, Mitchell MA, Rivera-Baltanás T, Botterill J, Olivares JM, Kalynchuk LE (2016) Reelin-related disturbances in depression: implications for translational studies. Front Cell Neurosci 10:48.

Chen X, Duan H, Xiao L, Gan J (2018) Genetic and epigenetic alterations underlie oligodendroglia susceptibility and white matter etiology in psychiatric disorders. Front Genet 9:565.

Choe Y, Huynh T, Pleasure SJ (2014) Migration of oligodendrocyte progenitor cells is controlled by transforming growth factor $\beta$ family proteins during corticogenesis. J Neurosci 34:14973-14983.

D’Arcangelo G, Nakajima K, Miyata T, Ogawa M, Mikoshiba K, Curran T (1997) Reelin is a secreted glycoprotein recognized by the CR-50 monoclonal antibody. J Neurosci 17:23-31.

D'Arcangelo G, Homayouni R, Keshvara L, Rice DS, Sheldon M, Curran T (1999) Reelin is a ligand for lipoprotein receptors. Neuron 24:471-479.

De Strooper B, Karran E (2016) The cellular phase of Alzheimer's disease. Cell 164:603-615.

Di Donato V, De Santis F, Albadri S, Auer TO, Duroure K, Charpentier M, Concordet J-P, Gebhardt C, Del Bene F (2018) An attractive Reelin gradient establishes synaptic lamination in the vertebrate visual system. Neuron 97:1049-1062.

Elbaz B, Popko B (2019) Molecular control of oligodendrocyte development. Trends Neurosci 42:263-277.

Emery B, Lu QR (2015) Transcriptional and epigenetic regulation of oligodendrocyte development and myelination in the central nervous system. Cold Spring Harb Perspect Biol 7:a020461.

Fields RD (2008) White matter in learning, cognition and psychiatric disorders. Trends Neurosci 31:361-370.

Folsom TD, Fatemi SH (2013) The involvement of Reelin in neurodevelopmental disorders. Neuropharmacology 68:122-135.

Fruttiger M, Karlsson L, Hall AC, Abramsson A, Calver AR, Boström H, Willetts K, Bertold CH, Heath JK, Betsholtz C, Richardson WD (1999) Defective oligodendrocyte development and severe hypomyelination in PDGF-A knockout mice. Development 126:457-467.

Frykman PK, Brown MS, Yamamoto T, Goldstein JL, Herz J (1995) Normal plasma lipoproteins and fertility in gene-targeted mice homozygous for a disruption in the gene encoding very low density lipoprotein receptor. Proc Natl Acad Sci USA 92:8453-8457.

Ge X, Xiao G, Huang H, Du J, Tao Y, Yang A, Wu H, Zhang Z, Qiu M (2019) Stage-dependent regulation of oligodendrocyte development and enhancement of myelin repair by dominant negative Master-mind 1 protein. Glia 67:1654-1666.

Hack I, Hellwig S, Junghans D, Brunne B, Bock HH, Zhao S, Frotscher M (2007) Divergent roles of ApoER2 and VLDLR in the migration of cortical neurons. Development 134:3883-3891.

Hashimoto-Torii K, Torii M, Sarkisian MR, Bartley CM, Shen J, Radtke F, Gridley T, Sestan N, Rakic P (2008) Interaction between Reelin and Notch signaling regulates neuronal migration in the cerebral cortex. Neuron 60:273-284. 
Hirota Y, Nakajima K (2017) Control of neuronal migration and aggregation by Reelin signaling in the developing cerebral cortex. Front Cell Dev Biol 5:40.

Hirota Y, Nakajima K (2020) VLDLR is not essential for Reelin-induced neuronal aggregation but suppresses neuronal invasion into the marginal zone. Development 147:dev189936.

Hughes EG, Kang SH, Fukaya M, Bergles DE (2013) Oligodendrocyte progenitors balance growth with self-repulsion to achieve homeostasis in the adult brain. Nat Neurosci 16:668-676.

Ishii K, Kubo K, Nakajima K (2016) Reelin and neuropsychiatric disorders. Front Cell Neurosci 10:229.

Jossin Y, Gui L, Goffinet AM (2007) Processing of Reelin by embryonic neurons is important for function in tissue but not in dissociated cultured neurons. J Neurosci 27:4243-4252.

Kessaris N, Fogarty M, Iannarelli P, Grist M, Wegner M, Richardson WD (2006) Competing waves of oligodendrocytes in the forebrain and postnatal elimination of an embryonic lineage. Nat Neurosci 9:173-179.

Kohno T, Ogino H, Yamakage Y, Hattori M (2020) Expression and preparation of recombinant Reelin and ADAMTS-3 proteins. Methods Mol Biol 2043:93-104.

Koie M, Okumura K, Hisanaga A, Kamei T, Sasaki K, Deng M, Baba A, Kohno T, Hattori M (2014) Cleavage within Reelin repeat 3 regulates the duration and range of the signaling activity of Reelin protein. J Biol Chem 289:12922-12930.

Kojima T, Nakajima K, Mikoshiba K (2000) The disabled 1 gene is disrupted by a replacement with L1 fragment in yotari mice. Brain Res Mol Brain Res 75:121-127.

Kupferman JV, Basu J, Russo MJ, Guevarra J, Cheung SK, Siegelbaum SA (2014) Reelin signaling specifies the molecular identity of the pyramidal neuron distal dendritic compartment. Cell 158:1335-1347.

Lane-Donovan C, Herz J (2017) The ApoE receptors VLDLR and ApoER2 in central nervous system function and disease. J Lipid Res 58:1036-1043.

LeVine SM, Torres MV (1993) Satellite oligodendrocytes and myelin are displaced in the cortex of the reeler mouse. Brain Res Dev Brain Res 75:279284.

Lorenzetto E, Panteri R, Marino R, Keller F, Buffelli M (2008) Impaired nerve regeneration in reeler mice after peripheral nerve injury. Eur J Neurosci 27:12-19.

Marshall CA, Suzuki SO, Goldman GE (2003) Gliogenic and neurogenic progenitors of the subventricular zone: who are they, where did they come from, and where are they going?. Glia 43:52-61.

Mayoral SR, Chan JR (2016) The environment rules: spatiotemporal regulation of oligodendrocyte differentiation. Curr Opin Neurobiol 39:47-52.

Meseke M, Neumüller F, Brunne B, Li X, Anstötz M, Pohlkamp T, Rogalla MM, Herz J, Rune GM, Bender RA (2018) Distal dendritic enrichment of HCN1 channels in hippocampal CA1 is promoted by estrogen, but does not require Reelin. eNeuro 5:ENEURO.0258-18.2018.

Mikoshiba K, Takamatsu K, Tsukada Y (1985) Altered myelinated fiber trajectory at various postnatal days in the cerebral cortex of reeler mice by immunohistochemical stain with MBP antiserum. Dev Neurosci 7:199205.

Mitew S, Hay CM, Peckham H, Xiao J, Koenning M, Emery B (2014) Mechanisms regulating the development of oligodendrocytes and central nervous system myelin. Neuroscience 276:29-47.

Miyamoto Y, Yamauchi J, Tanoue A (2008) Cdk5 phosphorylation of WAVE2 regulates oligodendrocyte precursor cell migration through nonreceptor tyrosine kinase Fyn. J Neurosci 28:8326-8337.

Nakano Y, Kohno T, Hibi T, Kohno S, Baba A, Mikoshiba K, Nakajima K, Hattori M (2007) The extremely conserved C-terminal region of Reelin is not necessary for secretion but is required for efficient activation of downstream signaling. J Biol Chem 282:20544-20552.

Ogino H, Hisanaga A, Kohno T, Kondo Y, Okumura K, Kamei T, Sato T, Asahara H, Tsuiji H, Fukata M, Hattori M (2017) Secreted metalloproteinase ADAMTS-3 inactivates Reelin. J Neurosci 37:3181-3191.
Okugawa E, Ogino H, Shigenobu T, Yamakage Y, Tsuiji H, Oishi H, Kohno T, Hattori M (2020) Physiological significance of proteolytic processing of Reelin revealed by cleavage-resistant Reelin knock-in mice. Sci Rep 10:4471.

Panteri R, Mey J, Zhelyaznik N, D'Altocolle A, Del Fà A, Gangitano C, Marino R, Lorenzetto E, Buffelli M, Keller F (2006) Reelin is transiently expressed in the peripheral nerve during development and is upregulated following nerve crush. Mol Cell Neurosci 32:133-142.

Pasten C, Cerda J, Jausoro I, Court FA, Cáceres A, Marzolo M-P (2015) ApoER2 and Reelin are expressed in regenerating peripheral nerve and regulate Schwann cell migration by activating the Racl GEF protein, Tiam1. Mol Cell Neurosci 69:1-11.

Ravanelli AM, Kearns CA, Powers RK, Wang Y, Hines JH, Donaldson MJ, Appel B (2018) Sequential specification of oligodendrocyte lineage cells by distinct levels of Hedgehog and Notch signaling. Dev Biol 444:93-106.

Sheldon M, Rice DS, D'Arcangelo G, Yoneshima H, Nakajima K, Mikoshiba K, Howell BW, Cooper JA, Goldowitz D, Curran T (1997) Scrambler and yotari disrupt the disabled gene and produce a reeler -like phenotype in mice. Nature 389:730-733.

Siebert JR, Osterhout DJ (2011) Oligodendroglial cells express and secrete Reelin. Anat Rec (Hoboken) 294:759-763.

Skarnes WC, Rosen B, West AP, Koutsourakis M, Bushell W, Iyer V, Mujica AO, Thomas M, Harrow J, Cox T, Jackson D, Severin J, Biggs P, Fu J, Nefedov M, de Jong PJ, Stewart AF, Bradley A (2011) A conditional knockout resource for the genome-wide study of mouse gene function. Nature 474:337-342.

Talebian S, Gharesouran J, Ghafouri-Fard S, Esfahani BS, Arsang-Jang S, Omrani MD, Taheri M, Rezazadeh M (2019) Assessment of expression of RELN signaling pathway in multiple sclerosis patients. Immunobiology 224:402-407.

Tan SS, Kalloniatis M, Truong HT, Binder MD, Cate HS, Kilpatrick TJ, Hammond VE (2009) Oligodendrocyte positioning in cerebral cortex is independent of projection neuron layering. Glia 57:1024-1030.

Tsai HH, Niu J, Munji R, Davalos D, Chang J, Zhang H, Tien AC, Kuo CJ, Chan JR, Daneman R, Fancy SP (2016) Oligodendrocyte precursors migrate along vasculature in the developing nervous system. Science 351:379-384

Uchida T, Baba A, Pérez-Martínez FJ, Hibi T, Miyata T, Luque JM, Nakajima K, Hattori M (2009) Downregulation of functional Reelin receptors in projection neurons implies that primary Reelin action occurs at early/ premigratory stages. J Neurosci 29:10653-10662.

Wasser CR, Herz J (2017) Reelin: neurodevelopmental architect and homeostatic regulator of excitatory synapses. J Biol Chem 292:1330-1338.

Winkler CC, Yabut OR, Fregoso SP, Gomez HG, Dwyer BE, Pleasure SJ, Franco SJ (2018) The dorsal wave of neocortical oligodendrogenesis begins embryonically and requires multiple sources of Sonic hedgehog. J Neurosci 38:5237-5250

Wolswijk G, Noble M (1992) Cooperation between PDGF and FGF converts slowly dividing O-2Aadult progenitor cells to rapidly dividing cells with characteristics of O-2Aperinatal progenitor cells. J Cell Biol 118:889-900.

Yasui N, Nogi T, Kitao T, Nakano Y, Hattori M, Takagi J (2007) Structure of a receptor-binding fragment of Reelin and mutational analysis reveal a recognition mechanism similar to endocytic receptors. Proc Natl Acad Sci USA 104:9988-9993.

Yoneshima H, Nagata E, Matsumoto M, Yamada M, Nakajima K, Miyata T, Ogawa M, Mikoshiba K (1997) A novel neurological mutant mouse, yotari, which exhibits reeler-like phenotype but expresses CR-50 antigen/ Reelin. Neurosci Res 29:217-223.

Zhao S, Hu X, Park J, Zhu Y, Zhu Q, Li H, Luo C, Han R, Cooper N, Qiu M (2007) Selective expression of LDLR and VLDLR in myelinating oligodendrocytes. Dev Dyn 236:2708-2712. 